University of Nebraska - Lincoln

DigitalCommons@University of Nebraska - Lincoln

\title{
A bioenergetics-based population dynamics model of Pacific herring (Clupea harengus pallasi) coupled to a lower trophic level nutrient-phytoplankton-zooplankton model: Description, calibration, and sensitivity analysis
}

\author{
Bernard A. Megrey \\ Alaska Fisheries Science Centerin \\ Kenneth A. Rose \\ Louisiana State University \\ Robert A. Klumb \\ U.S. Fish and Wildlife Service \\ Douglas E. Hay \\ Fisheries and Oceans Canada \\ Francisco E. Werner \\ University of North Carolina \\ See next page for additional authors \\ Follow this and additional works at: https://digitalcommons.unl.edu/usfwspubs \\ Part of the Aquaculture and Fisheries Commons
}

Megrey, Bernard A.; Rose, Kenneth A.; Klumb, Robert A.; Hay, Douglas E.; Werner, Francisco E.; Eslinger, David L.; and Smithg, S. Lan, "A bioenergetics-based population dynamics model of Pacific herring (Clupea harengus pallasi) coupled to a lower trophic level nutrient-phytoplankton-zooplankton model: Description, calibration, and sensitivity analysis" (2007). US Fish \& Wildlife Publications. 84.

https://digitalcommons.unl.edu/usfwspubs/84

This Article is brought to you for free and open access by the US Fish \& Wildlife Service at DigitalCommons@University of Nebraska - Lincoln. It has been accepted for inclusion in US Fish \& Wildlife Publications by an authorized administrator of DigitalCommons@University of Nebraska - Lincoln. 


\section{Authors}

Bernard A. Megrey, Kenneth A. Rose, Robert A. Klumb, Douglas E. Hay, Francisco E. Werner, David L. Eslinger, and S. Lan Smithg 


\title{
A bioenergetics-based population dynamics model of Pacific herring (Clupea harengus pallasi) coupled to a lower trophic level nutrient-phytoplankton-zooplankton model: Description, calibration, and sensitivity analysis
}

\author{
Bernard A. Megrey ${ }^{a, *}$, Kenneth A. Rose ${ }^{b}$, Robert A. Klumb ${ }^{c}$, Douglas E. Hay ${ }^{d}$, \\ Francisco E. Werner ${ }^{e}$, David L. Eslingerf ${ }^{f}$, S. Lan Smith ${ }^{g}$ \\ a National Oceanic and Atmospheric Administration, National Marine Fisheries Service, Alaska Fisheries Science Center, \\ 7600 Sand Point Way NE, Seattle, WA 98115, USA \\ $\mathrm{b}$ Department of Oceanography and Coastal Sciences, Coastal Fisheries Institute, Louisiana State University, Baton Rouge, LA 70803, USA \\ c U.S. Fish and Wildlife Service, Great Plains Fish \& Wildlife Management Assistance Office, 420 South Garfield Avenue Suite \#400, \\ Pierre, SD 57501-5408, USA \\ d Pacific Biological Station, Fisheries and Oceans Canada, 3190 Hammond Bay Road, Pacific Biological Station, Nanaimo, \\ British Columbia V9R 5K6, Canada \\ e Marine Sciences Department, CB\# 3300, University of North Carolina, Chapel Hill, NC 27599-3300, USA \\ ${ }^{f}$ NOAA Coastal Services Center, 2234 South Hobson Avenue, Charleston, SC 29405-2413, USA \\ g Ecosystem Change Research Program, Frontier Research Center for Global Change, JAMSTEC, 3173-25 Showamachi, Kanazawa-ku, \\ Yokohama, Kanagawa 236-0001, Japan
}

\section{A R T I C L E I N F O}

Article history:

Published on line 4 December 2006

Keywords:

Lower trophic level model

NEMURO

NEMURO.FISH

Bioenergetics

Population dynamics

Herring

Coupled marine ecosystem model

\begin{abstract}
A B S T R A C T
We describe an approach to dynamically couple a fish bioenergetics-based population dynamics model to the NEMURO lower trophic level nutrient-phytoplankton-zooplankton model. The coupled models, denoted NEMURO.FISH and configured for Pacific herring (Clupea harengus pallasii) on the west coast of Vancouver Island, are capable of simulating the daily dynamics of the lower trophic levels and the daily average weight and numbers of individual herring in each of 10 age classes over multiple years. New recruits to the herring population are added each June based on either constant recruitment or dynamic recruitment generated from an environmental Ricker spawner-recruitment relationship. The dynamics of the three zooplankton groups in the NEMURO model determine the consumption rate of the herring; herring consumption affects the zooplankton, and egestion and excretion contribute to the nitrogen dynamics. NEMURO was previously calibrated to field data for the West Coast Vancouver Island. Thirty-year simulations of herring growth and population dynamics were performed that used repeated environmental conditions for the lower trophic levels of NEMURO and historical environmental variables for the herring spawner-recruit relationship. Herring dynamics were calibrated to the west coast of Vancouver Island such that the coupled models reasonably duplicated observed herring weights-at-age and total herring biomass. Additional 30-year simulations under constant
\end{abstract}

\footnotetext{
* Corresponding author. Tel.: +1 206526 4147; fax: +1 2065266723.

E-mail address: bern.megrey@noaa.gov (B.A. Megrey).

0304-3800/\$ - see front matter @ 2006 Elsevier B.V. All rights reserved. doi:10.1016/j.ecolmodel.2006.08.020
} 
recruitment with herring coupled and uncoupled from NEMURO clearly showed the effects of the feedback mechanism between the two models and also showed that herring have small to moderate effects on their prey. Monte Carlo uncertainty analysis showed the importance of feeding- and respiration-related parameters to predicted individual and population herring growth. The utility of the NEMURO.FISH framework for improving our understanding of climate change effects on marine ecosystem dynamics is discussed.

(c) 2006 Elsevier B.V. All rights reserved.

\section{Introduction}

Predicting and understanding the effects of global climate change on ecosystems and fish production in oceanic systems is essential if we are to develop quantitative approaches to managing sustainable marine resources. There has been much discussion on the relative roles of top down (e.g., top predators) versus bottom up (e.g., climate change and resource limitation) regulation of marine ecosystems (Cury et al., 2000; Rejas et al., 2005; Ware and Thomson, 2005). The resolution of the roles of bottom-up versus top-down control remains elusive, and the importance of the impact of variability of physical forcing versus harvesting pressure on the structure and function of marine ecosystems remains unresolved in many instances. Field-based studies to establish the importance of the bottom-up and top-down controls are a difficult undertaking, given the complexity of even the smallest marine ecosystem. Such studies are even more difficult in continental shelf and open ocean domains, where the ecosystems under consideration exchange material with neighboring areas. Another approach to answering these questions is to use theoretical or simulation models to study the links between climate variability and its effects on marine ecosystems. Of particular interest is how climate effects propagate through the food web and affect the growth and population dynamics of pelagic fishes.

There are different variants of marine ecosystem massbalance or bioenergetic models (e.g., see Carlotti et al., 2000; Le Quéré et al., 2005 for reviews). In most situations, the objectives behind building a model dictate the system boundaries (i.e., which components of the model receive the most detailed attention and which components can be more or less ignored and treated as simple closure terms). Lower trophic level (LTL) nutrient-phytoplankton-zooplankton (NPZ) models are common representations of the marine ecosystem (Fennel and Neumann, 2004). They are formulated to describe and quantify biogeochemical cycling of elements and LTL dynamics, and generally consider the higher trophic levels (HTL) as an imposed closure/mortality term on the phyto- or zooplanktonic species. Adult fish bioenergetic models with completely closed life cycles (Rose et al., 1999), fish larvae early life history models (Vlymen, 1977; Beyer and Laurence, 1980), and fish individual-based models (Letcher et al., 1996) are also available. Typically, they begin with zooplankton food density as a driving force external to the model formulations. Since their focus is on fish, less attention is given to the nutrient and LTL food-web connections.

Despite the recognition by the oceanography scientific community that integration of knowledge across several trophic levels of the marine ecosystem is an important and necessary step, very few models effectively link LTL models to the commercially important fishes. Runge et al. (2004) point out that there are few examples of multi-trophic level coupled marine ecosystem models that allow for density-dependent interactions between trophic levels via numerical or functional response processes. We assert that only fully coupled multi-trophic level ecosystem models can be used to address the ever-present question of how climate change will impact biological productivity in the ocean.

The effective marriage of LTL NPZ models and HTL fulllife cycle fish models are rare, mainly due to the difficult practical and theoretical problems associated with resolving relevant temporal and spatial scales at all biologically meaningful trophic levels (Hermann et al., 2001). Many examples (Hinckley et al., 1996; Werner et al., 1996) have successfully combined LTL and HTL models but only in an uncoupled manner. To be relevant to the climate change question, fully coupled ecosystem models must include a description of the LTL food resource, predation by the HTL consumers, a mechanistic description of the dynamic feedback between the two, and a climate impact scenario.

In this paper we aim to address this identified deficiency. We coupled a LTL model, called NEMURO (North Pacific Ecosystem Model for Understanding Regional Oceanography; Kishi et al., 2007), with a "Wisconsin model" (Ney, 1993) bioenergetics formulation and a population dynamics model of Pacific herring (Clupea harengus pallasi), to examine how climate forcing propagates through the food web. The Wisconsin bioenergetics models, a suite of fish bioenergetics models developed by researchers associated with the University of Wisconsin Center for Limnology (Kitchell et al., 1977) are based on an energy balance equation that equates energy consumed with energy expended and gained. This approach is an alternative to other bioenergetic approaches such as dynamic energy budget models (Kooijman, 1993) and the metabolic theory of ecology (Brown et al., 2004), both of which use a unified theory of metabolism that scales easily to describe the dynamics of individuals, populations, communities and ecosystems and trophic webs. Wisconsin-based bioenergetics models (Hansen et al., 1993; Ney, 1993; Hanson et al., 1997) however, have been widely applied in fisheries science (Hartman and Brandt, 1995; Essington, 2003; Tang et al., 2003; and many others). Since our focus is the upper trophic level fish response to climate impacts we will rely on them here to describe herring dynamics.

The NEMURO model simulates the daily predator-prey interactions and biogeochemical cycling of phytoplankton, zooplankton, nutrients, and detritus. The herring model simulates the daily growth and mortality of herring in each of 10 age-classes, and is coupled to NEMURO via herring consumption dependent on zooplankton, and herring excretion and egestion contributing to the nitrogen cycle. The coupled 


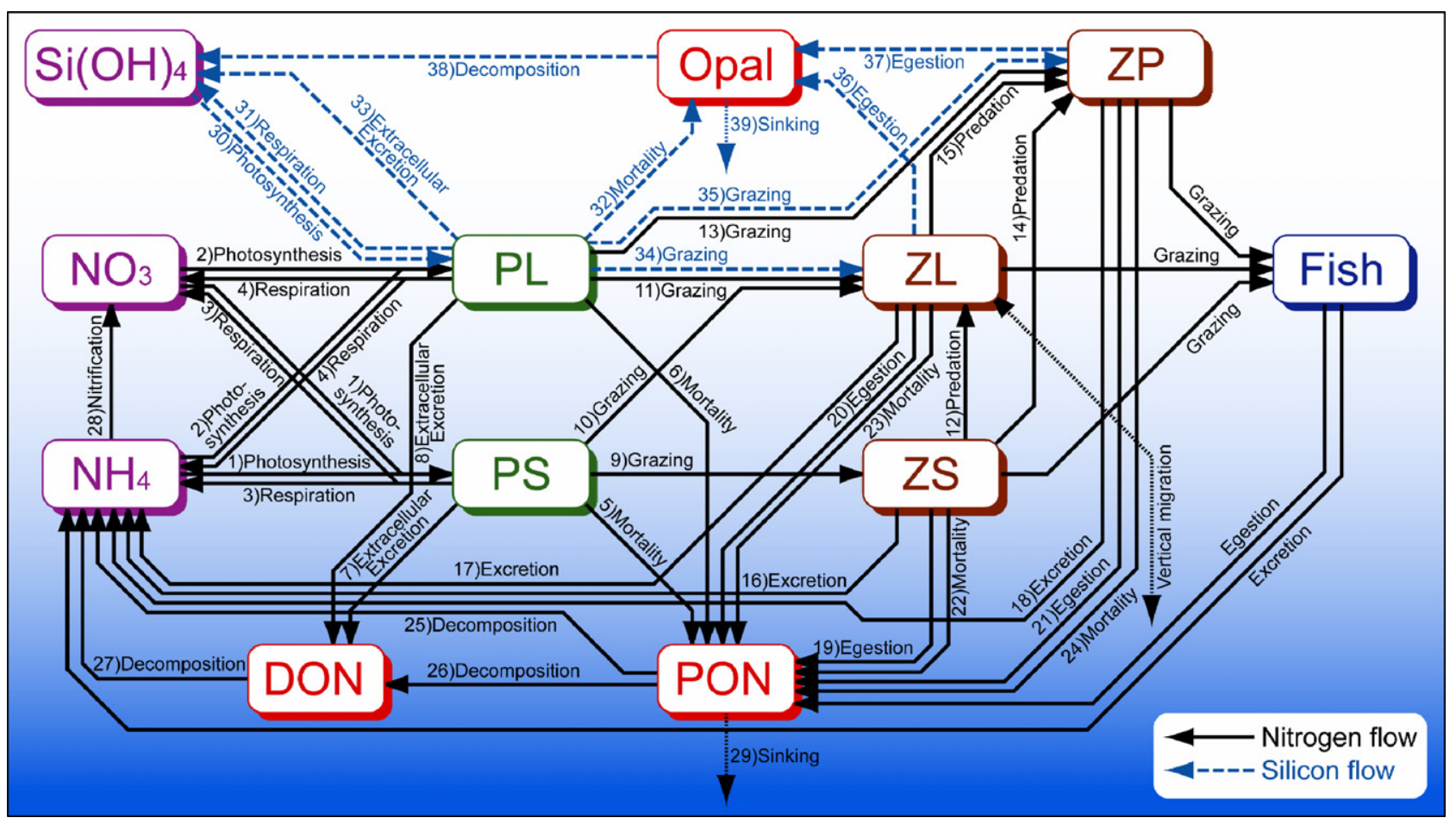

Fig. 1 - Schematic of NEMURO.FISH.

models (Fig. 1) are called NEMURO.FISH (NEMURO.for Including Saury and Herring). Ito et al. (2004, 2007) describes the saury version of the NEMURO.FISH model. The NEMURO and fish bioenergetics models can be solved simultaneously (coupled) or separately (uncoupled), allowing for investigation of the feedbacks between herring dynamics and their prey.

The NEMURO and fish bioenergetics model formulations are fairly generic. The NEMURO model has been applied to a variety of locations (e.g., Yamanaka et al., 2004; Kishi et al., 2004). We describe the fish model in the context of its application to Pacific herring in an upwelling system off the West Coast of Vancouver Island (WCVI). Herring were selected as a candidate fish species because they are commercially harvested, are well studied over their wide geographic range, are an ecologically important link between lower and higher trophic levels, and rely on zooplankton for food throughout their entire ontology. The WCVI herring population was selected because of the availability of LTL data (Robinson and Ware, 1999; Tanasichuk, 2002; Mackas et al., 2004), and longterm information on herring recruitment and weights-at-age (Hay et al., 2001; Schweigert, 2004).

In this paper, we describe the NEMURO.FISH model using the WCVI herring as an example and point the reader to Kishi et al. (2007) for a description of NEMURO. We focus on the fish component of NEMURO.FISH and the methods for dynamically coupling the NEMURO and fish models. Section 2 describes the bioenergetics-based population dynamics model, and its application to WCVI herring. Sections 3 and 4 describe the simulation methods, and Section 5 contains a description of how NEMURO.FISH was calibrated and results of a Monte Carlo uncertainty analysis of the coupled models. Section 6 summarizes our conclusions.

\section{Methods}

\subsection{NEMURO}

The NEMURO model implemented in this paper simulates the dynamics of the nutrient-phytoplankton-zooplankton food web in a single well-mixed spatial box that represents the surface layer of the water column (Fig. 1; Kishi et al., 2007). The food web is represented with eleven state variables: nitrate $\left(\mathrm{NO}_{3}\right)$, ammonium $\left(\mathrm{NH}_{4}\right)$, small phytoplankton (PS), large phytoplankton (PL), small zooplankton (ZS), large zooplankton (ZL), predatory zooplankton (ZP), particulate organic nitrogen (PON), dissolved organic nitrogen (DON), particulate organic silicate (Opal), and silicic acid $\left(\mathrm{Si}(\mathrm{OH})_{4}\right)$. All state variables are tracked in the units of mol Nl-1. NEMURO is a system of 11 coupled ordinary differential equations, with one equation describing the rate of change of each state variable.

The rate of change of each NEMURO state variable is expressed as the sum of process rates that affect that state variable. Photosynthesis, respiration, excretion, and mortality affect each phytoplankton state variable; grazing, egestion, excretion, and mortality affect each zooplankton state variable. Nutrient state variables are reduced by photosynthesis uptake, changed by various combinations of phytoplankton and zooplankton respiration, egestion, excretion, mortality, and converted among nutrient forms via first-order, temperature-dependent decomposition reactions. Phytoplankton photosynthesis, respiration, and mortality, and zooplankton grazing and other mortality, are all temperature-dependent. Photosynthesis also depends on the average light (integrated over the water column) and nitrate and ammonium concentrations, with photosynthesis 
of PL (diatom-like) also dependent on silicic acid $\left(\mathrm{Si}(\mathrm{OH})_{4}\right)$. Grazing is dependent on the concentrations of (sometimes multiple) prey using a temperature-dependent Ivlev formulation. Phytoplankton and zooplankton excretion is implicitly temperature-dependent because it is a function of photosynthesis.

\subsection{Fish bioenergetics}

The growth of an individual herring is followed daily as the difference between consumption and the losses due to respiration, specific dynamic action, egestion, excretion, and reproductive output. Formulas and parameters for the individual components in the bioenergetics model follow the terminology and symbols used in the Wisconsin bioenergetics models (Hanson et al., 1997). For some processes, we use formulations and parameter values specific to age-0 (youngof-the-year), age-1, and age-2+ (age-2 and older) herring. Bioenergetics models have been widely applied to freshwater and marine fish species (Ney, 1990, 1993; Hanson et al., 1997). Most model formulation and parameters for Pacific herring followed the approach used by Rudstam (1988) for Atlantic herring (C. harengus).

\subsubsection{Growth}

The growth rate of an individual Pacific age $i$ herring is calculated as weight increment per unit of weight per day:

$$
\frac{d W_{i}}{d t}=\left[C_{i}-\left(R_{i}+S_{i}+E G_{i}+E X_{i}\right)\right] \frac{C A L_{z}}{C A L_{f}} W_{i}-E G G_{i} W_{i},
$$

where for an age $i$ herring, $C_{i}$ is the consumption, $\mathrm{EX}_{i}$ the excretion or losses of nitrogenous excretory wastes, $E_{i}$ the egestion or losses due to feces, $R_{i}$ the respiration or losses through metabolism, $S_{i}$ the specific dynamic action or losses due to energy costs of digesting food, $E G G_{i}$ the fraction of body weight lost on the day of spawning, $W_{i}$ the weight of the fish (gwet weight), $t$ the time (d), CAL $L_{z}$ the energy density (J) of zooplankton (J g zooplankton ${ }^{-1}$ ), and $\mathrm{CAL}_{\mathrm{f}}$ is the energy density (J) of herring $\left(\mathrm{J} \mathrm{g} \mathrm{fish}^{-1}\right)$. Consumption, respiration, specific dynamic action, excretion, and egestion are in units of g prey g fish ${ }^{-1} \mathrm{~d}^{-1}$, which are converted to $\mathrm{g}$ fish $\mathrm{g}$ fish ${ }^{-1} \mathrm{~d}^{-1}$ by the ratio of the prey to herring energy densities. Terms for individual processes in Eq. (2.2.1.1) are described below. Values of fish-related parameters used in model simulations are shown in Table 1.

\subsubsection{Prey and herring energy density}

We used a fixed energy density for zooplankton and for age- 0 and age- 1 herring, and seasonally varying energy

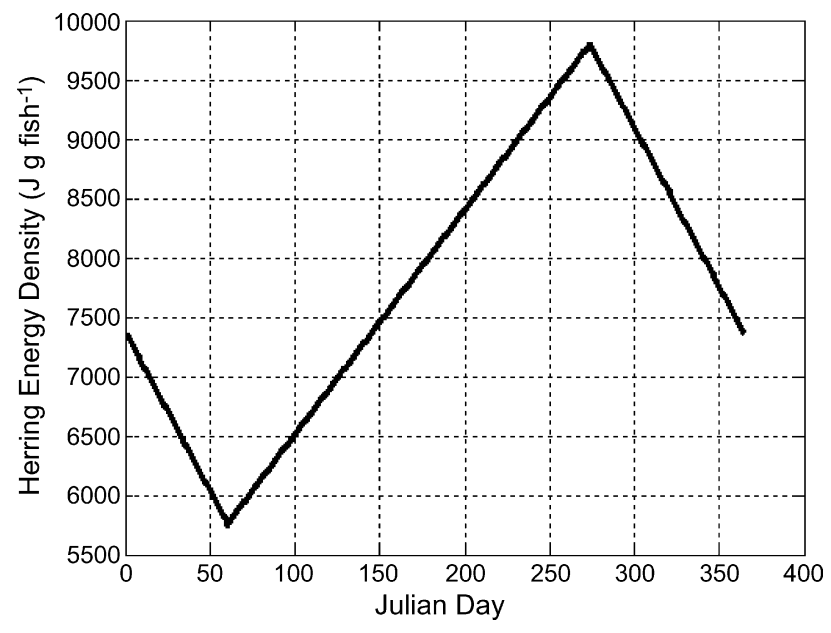

Fig. 2 - Straight line approximation to a seasonal energy density curve for Pacific herring.

for marine copepods (Laurence, 1976), where $1 \mathrm{cal}=4.18 \mathrm{~J}$. In comparison, Aneer (1980) used an energy density estimate of $3800 \mathrm{Jg}_{\text {z zooplankton }}{ }^{-1}$ (909 $\mathrm{cal} \mathrm{g} \mathrm{zooplankton}^{-1}$ ) for a mixed prey assemblage. While young herring exhibit a seasonal energy cycle (Paul and Paul, 1998; Paul et al., 1998), for simplicity, we assumed a constant energy density of $4460 \mathrm{~J} \mathrm{~g}$ fish $^{-1}$ wet wt for age- 0 and age- 1 herring. (Foy and Paul, 1999).

We chose to describe the energy density of age-2+ herring $\left(\mathrm{CAL}_{\mathrm{f}}, \mathrm{Jg}_{\mathrm{fish}}{ }^{-1}\right)$ as changing seasonally. Research has shown that energy density of clupeids varies seasonally, peaking in fall and declining through winter with lower energy densities for age-0 compared to older fish (Flath and Diana, 1985; Arrhenius and Hansson, 1996; Arrhenius, 1998b; Paul et al., 1998). Higher energy densities were found for Pacific herring off Alaska (Paul et al., 1998; Foy and Paul, 1999) compared to Great Lakes alewives and Baltic Sea clupeids. Paul et al. (1998) found age-2+ Pacific herring energy density peaked at $9800 \mathrm{~J} \mathrm{~g} \mathrm{fish}^{-1}$ (range: 9400-10 200) in fall (1 October) just after summer feeding, and decreased after that, reaching a minimum in spring ( 1 March) after spawning of about $5750 \mathrm{~J} \mathrm{~g} \mathrm{fish}^{-1}$ (range: 5200-6300). Females had higher energy densities in both seasons than males by $200-400 \mathrm{~J} \mathrm{~g} \mathrm{fish}^{-1}$. These seasonal changes are a result of feeding-related fat deposition. Based upon Paul et al. (1998), we constructed a piece-wise linear function for the energy density $\left(\mathrm{CAL}_{\mathrm{f}}, \mathrm{Jg}_{\mathrm{fish}}{ }^{-1}\right)$ of age-2+ herring (Fig. 2):

$$
\mathrm{CAL}_{\mathrm{f}}= \begin{cases}9800+\left((90+\text { jday }) \frac{(5750-9800)}{151}\right) & \text { if jday }<60 \\ \left.5750+(\text { (jday }-60) \frac{(9800-5750)}{274-60}\right) & \text { if jday } \geq 60 \text { and jday }<274, \\ \left.9800+(\text { (jday }-274) \frac{(5750-9800)}{151}\right) & \text { if jday } \geq 274\end{cases}
$$

density for age-2+ herring. We set $\mathrm{CAL}_{z}$ based on a typical value of $2580 \mathrm{Jg}$ zooplankton ${ }^{-1}$ (617.22 cal g zooplankton ${ }^{-1}$ ) where jday is the calendar day of the year ( 1 January =1, 2 January $=2$, etc.). 
Table 1 - Summary of parameter values and initial conditions used in the herring bioenergetics-based population dynamics model

\begin{tabular}{|c|c|c|}
\hline Symbol & Parameter description & Value \\
\hline \multicolumn{3}{|c|}{ Consumption (C) } \\
\hline$a_{C}$ & Intercept for $C_{\max }$ at $($ te $1+$ te 3$) / 2$ & 0.642 \\
\hline$b_{C}$ & coefficient for $C_{\max }$ vs. weight & 0.256 \\
\hline te1 & Temperature for xk1 $\left({ }^{\circ} \mathrm{C}\right)$ & $1.0^{\mathrm{a}}, 1.0^{\mathrm{b}}, 1.0^{\mathrm{c}}$ \\
\hline te2 & Temperature for xk2 $\left({ }^{\circ} \mathrm{C}\right)$ & $15.0^{\mathrm{a}}, 15.0^{\mathrm{b}}, 13.0^{\mathrm{c}}$ \\
\hline te3 & Temperature for xk3 $\left({ }^{\circ} \mathrm{C}\right)$ & $17.0^{\mathrm{a}}, 17.0^{\mathrm{b}}, 15.0^{\mathrm{c}}$ \\
\hline te4 & Temperature for xk4 $\left({ }^{\circ} \mathrm{C}\right)$ & $23.0^{\mathrm{a}}, 25.0^{\mathrm{b}}, 23.0^{\mathrm{c}}$ \\
\hline $\mathrm{xk} 1$ & Proportion of $\mathrm{C}_{\max }$ at te 1 & $0.10^{\mathrm{a}, \mathrm{b}, \mathrm{c}}$ \\
\hline $\mathrm{xk} 2$ & Proportion of $\mathrm{C}_{\max }$ at te 2 & $0.98^{\mathrm{a}, \mathrm{b}, \mathrm{c}}$ \\
\hline xk3 & Proportion of $\mathrm{C}_{\max }$ at te 3 & $0.98^{a, b, c}$ \\
\hline $\mathrm{xk} 4$ & Proportion of $C_{\max }$ at te 4 & $0.01^{\mathrm{a}, \mathrm{b}, \mathrm{c}}$ \\
\hline \multicolumn{3}{|c|}{ Metabolism (R) } \\
\hline$a_{\mathrm{R}}$ & Intercept for $\mathrm{R}$ & $0.00528^{a}, 0.0033^{b, c}$ \\
\hline$b_{\mathrm{R}}$ & Coefficient for R vs. weight & $0.007^{a}, 0.227^{b, c}$ \\
\hline$c_{R}$ & Coefficient for $\mathrm{R}$ vs. temperature & $0.083^{a}, 0.0548^{b, c}$ \\
\hline$d_{R}$ & Coefficient for R vs. swimming speed & $0.0^{\mathrm{a}}, 0.03^{\mathrm{b}, \mathrm{c}}$ \\
\hline SDA & Coefficient for specific dynamic action & $0.125^{\mathrm{a}}, 0.175^{\mathrm{d}}$ \\
\hline \multicolumn{3}{|c|}{ Swimming speed $(U)$} \\
\hline$a_{\mathrm{A}}$ & Intercept $U(<\mathrm{ktu})\left(\mathrm{cm} \mathrm{s}^{-1}\right)$ & $1.0^{\mathrm{a}}, 3.9^{\mathrm{b}, \mathrm{c}}$ \\
\hline$a_{\mathrm{A}}$ & Intercept $U(\geq \mathrm{ktu})\left(\mathrm{cm} \mathrm{s}^{-1}\right)$ & $1.0^{\mathrm{a}}, 15.0^{\mathrm{b}, \mathrm{c}}$ \\
\hline$b_{\mathrm{A}}$ & Coefficient U vs. weight & $0.0^{\mathrm{a}}, 0.13^{\mathrm{b}, \mathrm{c}}$ \\
\hline$c_{A}$ & Coefficient U vs. temperature (<ktu) & $0.0^{\mathrm{a}}, 0.149^{\mathrm{b}, \mathrm{c}}$ \\
\hline$c_{A}$ & Coefficient $U$ vs. temperature ( $\geq \mathrm{ktu})$ & $0.0^{\mathrm{a}}, 0.0^{\mathrm{b}, \mathrm{c}}$ \\
\hline ktu & Cutoff temperature for swimming speed coefficients for age- $1+\left({ }^{\circ} \mathrm{C}\right)$ & 9.0 \\
\hline \multicolumn{3}{|c|}{ Egestion and excretion (EG and EX) } \\
\hline$a_{\mathrm{F}}$ & Proportion of consumed food egested & $0.125^{\mathrm{a}}, 0.16^{\mathrm{d}}$ \\
\hline$a_{\mathrm{E}}$ & Proportion of consumed food excreted & $0.078^{\mathrm{a}}, 0.10^{\mathrm{d}}$ \\
\hline \multicolumn{3}{|c|}{ Multispecies functional response } \\
\hline$v_{11}$ & Vulnerability of ZS to age-0 & 1.0 \\
\hline$v_{12}$ & Vulnerability of ZS to age-1 & 0.5 \\
\hline$v_{13}$ & Vulnerability of ZS to age-2+ & 0.0 \\
\hline$v_{21}$ & Vulnerability of ZL to age-0 & 0.1 \\
\hline$v_{22}$ & Vulnerability of ZL to age-1 & 1.0 \\
\hline$v_{23}$ & Vulnerability of ZL to age-2+ & 0.5 \\
\hline$v_{31}$ & Vulnerability of ZP to age-0 & 0.0 \\
\hline$v_{32}$ & Vulnerability of ZP to age-1 & 0.5 \\
\hline$v_{33}$ & Vulnerability of ZP to age-2+ & 1.0 \\
\hline$K_{11}$ & Half saturation constant for ZS to age-0 (g wet weight $\mathrm{m}^{-3}$ ) & 0.15 \\
\hline$K_{12}$ & Half saturation constant for ZS to age-1 (g wet weight $\mathrm{m}^{-3}$ ) & 1.15 \\
\hline$K_{13}$ & Half saturation constant for $\mathrm{ZS}$ to age-2+(g wet weight $\left.\mathrm{m}^{-3}\right)$ & 0.78 \\
\hline$K_{21}$ & Half saturation constant for ZL to age-0 (g wet weight m ${ }^{-3}$ ) & 0.15 \\
\hline $\mathrm{K}_{22}$ & Half saturation constant for ZL to age-1 (g wet weight $\mathrm{m}^{-3}$ ) & 1.15 \\
\hline$K_{23}$ & Half saturation constant for ZL to age-2+ (g wet weight $\left.\mathrm{m}^{-3}\right)$ & 0.78 \\
\hline$K_{31}$ & Half saturation constant for ZP to age-0 (gwet weight $\mathrm{m}^{-3}$ ) & 0.35 \\
\hline$K_{32}$ & Half saturation constant for ZP to age-1 (g wet weight $\mathrm{m}^{-3}$ ) & 1.15 \\
\hline$K_{33}$ & Half saturation constant for ZP to age-2+(g wet weight $\left.\mathrm{m}^{-3}\right)$ & 0.78 \\
\hline \multicolumn{3}{|c|}{ Population dynamics } \\
\hline $\mathrm{M}_{1}$ & Natural mortality for age-1 (year ${ }^{-1}$ ) & 0.44 \\
\hline $\mathrm{M}_{2}$ & Natural mortality for age-2 (year $\left.{ }^{-1}\right)$ & 0.44 \\
\hline$M_{3}$ & Natural mortality for age-3 $\left(\right.$ year $^{-1}$ ) & 0.44 \\
\hline $\mathrm{M}_{4}$ & Natural mortality for age-4 year $^{-1}$ ) & 0.44 \\
\hline $\mathrm{M}_{5}$ & Natural mortality for age-5 $\left(\right.$ year $^{-1}$ ) & 0.44 \\
\hline$M_{6}$ & Natural mortality for age- 6 (year ${ }^{-1}$ ) & 0.44 \\
\hline$M_{7}$ & Natural mortality for age-7 (year ${ }^{-1}$ ) & 0.44 \\
\hline$M_{8}$ & Natural mortality for age-8 $\left(\right.$ year $^{-1}$ ) & 0.44 \\
\hline $\mathrm{M}_{9}$ & Natural mortality for age-9 (year $^{-1}$ ) & 0.44 \\
\hline $\mathrm{M}_{10}$ & Natural mortality for age-10 (year ${ }^{-1}$ ) & 0.44 \\
\hline$F_{1}$ & Fishing mortality for age-1 (year ${ }^{-1}$ ) & 0.0 \\
\hline$F_{2}$ & Fishing mortality for age-2 (year $^{-1}$ ) & 0.0 \\
\hline$F_{3}$ & Fishing mortality for age-3 $\left(\right.$ year $\left.^{-1}\right)$ & 0.0 \\
\hline$F_{4}$ & Fishing mortality for age-4 $\left(\right.$ year $\left.^{-1}\right)$ & 0.25 \\
\hline
\end{tabular}


Table 1 (Continued)

\begin{tabular}{|c|c|c|}
\hline Symbol & Parameter description & Value \\
\hline$F_{5}$ & Fishing mortality for age- 5 (year ${ }^{-1}$ ) & 0.25 \\
\hline$F_{6}$ & Fishing mortality for age- 6 (year ${ }^{-1}$ ) & 0.25 \\
\hline$F_{7}$ & Fishing mortality for age-7 (year ${ }^{-1}$ ) & 0.25 \\
\hline$F_{8}$ & Fishing mortality for age- 8 (year ${ }^{-1}$ ) & 0.25 \\
\hline$F_{9}$ & Fishing mortality for age- $9\left(\right.$ year $\left.^{-1}\right)$ & 0.25 \\
\hline$F_{10}$ & Fishing mortality for age- 10 (year ${ }^{-1}$ ) & 0.25 \\
\hline $\mathrm{Kmat}_{1}$ & Maturity for age-1 (\%) & 0.0 \\
\hline $\mathrm{Kmat}_{2}$ & Maturity for age-2 (\%) & 0.0 \\
\hline $\mathrm{Kmat}_{3}$ & Maturity for age-3 (\%) & 0.95 \\
\hline $\mathrm{Kmat}_{4}$ & Maturity for age-4 (\%) & 1.0 \\
\hline $\mathrm{Kmat}_{5}$ & Maturity for age-5 (\%) & 1.0 \\
\hline $\mathrm{Kmat}_{6}$ & Maturity for age- $6(\%)$ & 1.0 \\
\hline $\mathrm{Kmat}_{7}$ & Maturity for age-7 (\%) & 1.0 \\
\hline $\mathrm{Kmat}_{8}$ & Maturity for age- $8(\%)$ & 1.0 \\
\hline Kmat9 $_{9}$ & Maturity for age- $9(\%)$ & 1.0 \\
\hline $\mathrm{Kmat}_{10}$ & Maturity for age-10 (\%) & 1.0 \\
\hline elhm & Early life history mortality from egg to age-2 (year-1) & 0.58 \\
\hline \multicolumn{3}{|c|}{ Initial conditions } \\
\hline $\mathrm{N}_{1}$ & Initial number of age- 1 (number $\mathrm{m}^{-3}$ ) & $5.0 \mathrm{E}-03$ \\
\hline $\mathrm{N}_{2}$ & Initial number of age-2 (number $\mathrm{m}^{-3}$ ) & $3.22 \mathrm{E}-04$ \\
\hline $\mathrm{N}_{3}$ & Initial number of age-3 (number $\mathrm{m}^{-3}$ ) & 2.07E-04 \\
\hline $\mathrm{N}_{4}$ & Initial number of age- 4 (number $\mathrm{m}^{-3}$ ) & $1.34 \mathrm{E}-04$ \\
\hline$N_{5}$ & Initial number of age- 5 (number $\mathrm{m}^{-3}$ ) & $6.70 \mathrm{E}-05$ \\
\hline$N_{6}$ & Initial number of age- 6 (number $\mathrm{m}^{-3}$ ) & $3.36 \mathrm{E}-05$ \\
\hline $\mathrm{N}_{7}$ & Initial number of age-7 (number $\mathrm{m}^{-3}$ ) & $1.69 \mathrm{E}-05$ \\
\hline$N_{8}$ & Initial number of age- 8 (number $\mathrm{m}^{-3}$ ) & $8.45 \mathrm{E}-06$ \\
\hline$N_{9}$ & Initial number of age- 9 (number $\mathrm{m}^{-3}$ ) & $4.24 \mathrm{E}-06$ \\
\hline$N_{10}$ & Initial number of age- 10 (number $\mathrm{m}^{-3}$ ) & $2.13 \mathrm{E}-06$ \\
\hline $\mathrm{W}_{1}$ & Initial size of age-1 ( $g$ wet weight $\mathrm{m}^{-3}$ ) & 0.2 \\
\hline $\mathrm{W}_{2}$ & Initial size of age-2 (g wet weight $\mathrm{m}^{-3}$ ) & 60.0 \\
\hline $\mathrm{W}_{3}$ & Initial size of age- 3 (g wet weight $\mathrm{m}^{-3}$ ) & 80.0 \\
\hline $\mathrm{W}_{4}$ & Initial size of age- 4 (g wet weight $\mathrm{m}^{-3}$ ) & 125.0 \\
\hline $\mathrm{W}_{5}$ & Initial size of age- 5 (g wet weight $\mathrm{m}^{-3}$ ) & 140.0 \\
\hline $\mathrm{W}_{6}$ & Initial size of age- 6 (g wet weight $\mathrm{m}^{-3}$ ) & 150.0 \\
\hline $\mathrm{W}_{7}$ & Initial size of age-7 (g wet weight $\mathrm{m}^{-3}$ ) & 170.0 \\
\hline $\mathrm{W}_{8}$ & Initial size of age-8 (g wet weight $\mathrm{m}^{-3}$ ) & 180.0 \\
\hline $\mathrm{W}_{9}$ & Initial size of age- 9 ( $\mathrm{g}$ wet weight $\mathrm{m}^{-3}$ ) & 190.0 \\
\hline $\mathrm{W}_{10}$ & Initial size of age-10 (g wet weight $\mathrm{m}^{-3}$ ) & 200.0 \\
\hline \multicolumn{3}{|c|}{ Exogenous variables } \\
\hline$L$ & Light (ly $\left.\min ^{-1}\right)$ & Eq. (2.6.1) \\
\hline TEMP & Sea surface temperature $\left({ }^{\circ} \mathrm{C}\right)$ & Eq. (2.6.2) \\
\hline SST & Sea surface temperature for spawning $\left({ }^{\circ} \mathrm{C}\right)$ & Eq. $(2.4 .3 .2)$ \\
\hline AIR & Air temperature for spawning $\left({ }^{\circ} \mathrm{C}\right)$ & Eq. (2.4.3.2) \\
\hline NPPI & North Pacific Pressure Index & Eq. (2.4.3.2) \\
\hline
\end{tabular}

Values in bold are calibrated values.

${ }^{a}$ Values for age group 0 herring.

$\mathrm{b}$ Values for age group 1 herring.

c Values for age group 2 and older herring.

$\mathrm{d}$ Values for age group 1 and older herring.

\subsubsection{Consumption}

Daily consumption rate (g preyg fish ${ }^{-1} \mathrm{~d}^{-1}$ ) was determined as the proportion of a maximum daily consumption rate that depended on herring weight and water temperature:

$C_{\max }=a_{C} W_{i}^{-b_{C}} f_{C}(T)$,

where $C_{\max }$ is the maximum consumption rate (g prey g fish ${ }^{-1} \mathrm{~d}^{-1}$ ), $f_{\mathrm{C}}(\mathrm{T})$ a temperature-dependence function for consumption (Eq. (2.2.4.1)), $\mathrm{T}$ the water temperature $\left({ }^{\circ} \mathrm{C}\right)$, $\mathrm{W}_{\mathrm{i}}$ the mass of an age $i$ herring ( $\mathrm{g}$ wet weight), $a_{\mathrm{C}}$ the intercept of the allometric mass function (for a $1 \mathrm{~g}$ fish at the optimal temperature), and $b_{C}$ is the slope of the allometric mass function. Weight-related parameters of maximum daily consumption rate are usually estimated from ad libitum feeding experiments conducted at the optimum temperature (Hanson et al., 1997). Rudstam (1988) used the slope and intercept derived by De Silva and Balbontin (1974) for the processes in the bioenergetics model for adult Atlantic herring $C$. harengus consumption. We specified single values of $a_{C}$ and $b_{C}$ for all herring age classes based on adult herring (Table 1); only limited data were available on larval and juvenile herring 
maximum consumption rates (Rudstam, 1988; Arrhenius, 1998a; Klumb, 2003; Maes et al., 2005). Realized consumption was calculated by applying (2.2.3.1) to a multispecies function response formulation given in Eqs. (2.3.1) and (2.3.2).

\subsubsection{Temperature dependence of maximum consumption}

For cool and cold-water species, maximum consumption temperature dependence in bionergetics models is generally modeled as a dome shaped-like curve proposed by Thornton and Lessem (1978). The Thornton and Lessem function is the product of two sigmoid curves: one curve is fit to the increasing segment of the temperature dependence function (gcta) and a different curve is fit to the decreasing segment (gctb).

$f_{C}(T)=$ gcta $\times$ gctb

where $\mathrm{T}$ is the water temperature $\left({ }^{\circ} \mathrm{C}\right)$ and

$\mathrm{tt} 5=\frac{1}{\mathrm{te} 2-\mathrm{te} 1}$

$\mathrm{t} 5=\mathrm{tt} 5 \times \ln \left[\frac{\mathrm{xk} 2(1.0-\mathrm{xk} 1)}{\mathrm{xk} 1(1.0-\mathrm{xk} 2)}\right]$,

$\mathrm{t} 4=\mathrm{e}^{[\mathrm{t} 5(\mathrm{~T}-\mathrm{te} 1)]}$,

$\mathrm{tt} 7=\frac{1}{\mathrm{te} 4-\mathrm{te} 3}$,

$\mathrm{t} 7=\mathrm{tt} 7 \times \ln \left[\frac{\mathrm{xk} 3(1.0-\mathrm{xk} 4)}{\mathrm{xk} 4(1.0-\mathrm{xk} 3)}\right]$

$t 6=e^{[t 7(t e 4-T)]}$,

$\operatorname{gcta}=\frac{\mathrm{xk} 1 \times \mathrm{t} 4}{(1.0+\mathrm{xk} 1(\mathrm{t} 4-1.0))}$

$\operatorname{gctb}=\frac{\mathrm{xk} 4 \times \mathrm{t} 6}{(1.0+\mathrm{xk} 4(\mathrm{t} 6-1.0))}$

Defining the shape of the curve involves specifying eight parameters: four water temperatures, and the percentages of maximum consumption associated with each temperature. For the increasing part of the curve, te 1 is the lower temperature at which the temperature dependence is a small fraction (xk1) of the maximum rate, and te2 is the water temperature corresponding to a large fraction (xk2) of the maximum consumption rate. For the decreasing portion of the curve, te 3 is the water temperature ( $\geq$ te 2$)$ at which dependence is a fraction (xk3) of the maximum and te 4 is the temperature at which dependence is some reduced fraction $\left(\mathrm{xk}_{4}\right)$ of the maximum rate. We used three different sets of the eight parameters, corresponding to age- $0,-1$, and $-2+$ herring (Table 1). Proportion parameters are from Arrhenius (1998a) and temperatures parameters are from Arrhenius (1998a) for age group 0 and from Rudstam (1988) for the other age groups.

\subsubsection{Respiration}

Respiration or metabolic rate is dependent on body weight, water temperature, and activity (swimming speed). We chose an allometric function to represent standard metabolism and multiplied it by a temperature function and an activity factor to estimate total respiration costs:

$R_{i}=a_{R} W_{i}^{-b_{R}} f_{R}(T) \times$ activity $\times 5.258$,

where for an age $i$ herring, $R_{i}$ is the resting respiration (i.e., standard metabolism) (g prey $g$ fish $^{-1} \mathrm{~d}^{-1}$ ), $W_{i}$ the wet weight (g) of an age $i$ herring, $f_{R}(T)$ the temperature dependence function for respiration, $\mathrm{T}$ the temperature $\left({ }^{\circ} \mathrm{C}\right), a_{\mathrm{R}}$ the intercept of the allometric mass function and represents the respiration rate of a $1 \mathrm{~g}$ fish at $0{ }^{\circ} \mathrm{C}$ and no activity, $b_{R}$ the slope of the allometric mass function for standard metabolism, and activity is the activity multiplier $\geq 1$. The coefficient 5.258 converts $\mathrm{gO}_{2} \mathrm{~g}_{\text {fish }}{ }^{-1} \mathrm{~d}^{-1}$ from Eq. (2.2.5.1) into g prey g fish ${ }^{-1} \mathrm{~d}^{-1}$ using the following conversion:

$\frac{13560 \mathrm{~J}}{\mathrm{~g}\left(\mathrm{O}_{2}\right)} \times \frac{1 \mathrm{gzoop}}{2580 \mathrm{~J}}=5.258 \mathrm{gzoop} g\left(\mathrm{O}_{2}\right)^{-1}$

The temperature dependence of respiration is a simple exponential relationship:

$f_{R}(T)=e^{c_{R} T}$

where $c_{R}$ approximates the $Q_{10}$ (the rate at which the function increases over relatively cool water temperatures). We represented activity as a function of body weight, conditioned on water temperature:

activity $=\mathrm{e}^{d_{\mathrm{R}} U}$,

where $U$ is the swimming speed in $\mathrm{cm} \mathrm{s}^{-1}$ and $d_{R}$ is a coefficient relating swimming speed to metabolism. Swimming speed is calculated as a function of body weight and temperature using

$U=a_{\mathrm{A}} W^{b_{\mathrm{A}}} \mathrm{e}^{c_{\mathrm{A}} \mathrm{T}}$.

Activity rates of fishes vary widely with growth rate and food density (Ware, 1975) while laboratory measurements of metabolism during activity may be higher than actual costs in the wild since larvae are passively moved by water currents. Exponential functions have typically been used to model activity costs of adult Atlantic herring (Rudstam, 1988). The exponential model of activity is comprised of three components: (1) $U$, which is the weight dependence of swimming speed $\left(\mathrm{cm} \mathrm{s}^{-1}\right),(2)$ the temperature dependence of swimming speed $\left(c_{A}\right)$, and (3) the relation of respiration to swimming speed $\left(d_{R}\right)$. The parameter $a_{A}$ is the intercept $\left(\mathrm{cm} \mathrm{s}^{-1}\right)$ for a $1 \mathrm{~g}$ fish at $0^{\circ} \mathrm{C}$. Swimming speeds of age- $1+$ Atlantic herring were only dependent on weight for temperatures warmer than $9^{\circ} \mathrm{C}$ (Rudstam, 1988). Klumb et al. (2003) used routine metabolism parameters without an activity multiplier in a bioenergetics model for age- 0 alewife.

Values of weight-related respiration parameters $\left(a_{R}, b_{R}\right)$ were specified separately for age- 0 and age- $1+$ herring, and parameters related to activity $\left(a_{\mathrm{A}}, b_{\mathrm{A}}, c_{\mathrm{A}}\right)$ were specified separately for age-0, age-1, and age-2+ herring after (Rudstam, 1988), with parameter values chosen so that temperaturedependence was eliminated above $9^{\circ} \mathrm{C}$ (Table 1$)$. 
General information on $b_{R}$ is available for adult fish, and typical values are $0.25-0.15$ (Winberg, 1956). For clupeids, slopes of the metabolism-weight relationship $\left(b_{R}\right)$ are 0.19-0.28 for Atlantic menhaden, Brevoorita tyrannus (Hettler, 1976), 0.215 for alewife (Stewart and Binkowski, 1986), and 0.227 for Atlantic herring (De Silva and Balbontin, 1974). Rudstam (1988) used 0.227 in the adult Atlantic herring bioenergetics model, and this value has also been applied to age- 0 herring (Kerr and Dickie, 1985; Arrhenius, 1998a). The relation of respiration to weight of fishes has been found to change ontogenetically, with isometric (mass independent) relations for larvae switching to negative allometries in adults (Post and Lee, 1996). Values for herring respiration parameters used in Eq. (2.2.5.1) are based on laboratory studies carried out by Klumb et al. (2003).

\subsubsection{Specific dynamic action}

Specific dynamic action is part of total respiration and represents the energy allocated to the digestive processes of food, principally the deamination of proteins but also the absorption, transportation, and deposition of food (Beamish, 1974). We formulated specific dynamic action as

$\mathrm{S}_{\mathrm{i}}=\mathrm{SDA}_{\mathrm{i}}\left(C_{\mathrm{i}}-\mathrm{EG}_{\mathrm{i}}\right)$

where, for an age $i$ herring, $S_{i}$ is the specific dynamic action (gpreyg fish ${ }^{-1} \mathrm{~d}^{-1}$ ), $\mathrm{SDA}_{i}$ the specific dynamic action coefficient, $C_{i}$ the consumption rate (gprey g fish ${ }^{-1} \mathrm{~d}^{-1}$ ) and $E G_{i}$ is the egestion rate (gpreyg fish ${ }^{-1} \mathrm{~d}^{-1}$ ). The parameter SDA in our model is the proportion of assimilated energy lost to specific dynamic action. In general laboratory studies show that it can range from 3 to $41 \%$ depending on diet, meal size, body weight and temperature (Beamish and Trippel, 1990). For adult Atlantic herring (Rudstam, 1988), SDA was assumed to be $17.5 \%$ based on data for aholehole Kuhlia sandvicensis (Muir and Niimi, 1972). Arrhenius (1998a) lowered SDA to $15 \%$ for age-0 Atlantic herring. Larval clupeids have been found to assimilate food more efficiently than adults (Kiørboe et al., 1987). In energetic terms, Kiørboe et al. (1987) estimated SDA for larval Atlantic herring to be $10 \%$ of assimilated ration. To accommodate this ontogenetic shift, we used separate values of SDA for an age- 0 and age- $1+$ herring. The value for age- 0 was set to $12.5 \%$, the mean of $10 \%$ reported by Arrhenius (1998a) and the $15 \%$ reported by Kiørboe et al. (1987). The value for age-1+ was set to $17.5 \%$, as reported by Rudstam (1988) (Table 1).

\subsubsection{Egestion and excretion}

Egestion was modeled as a constant proportion $\left(a_{F}\right)$ of consumption:

$\mathrm{EG}_{i}=a_{\mathrm{F}} C_{i}$

In the Atlantic herring models (Rudstam, 1988), egestion (gpreyg fish ${ }^{-1} \mathrm{~d}^{-1}$ ) was assumed to be $16 \%$ of consumption (gpreyg fish ${ }^{-1} \mathrm{~d}^{-1}$ ). The proportion of consumption egested has been found to be relatively low in larval and juvenile clupeids (Kiørboe et al., 1987; Limburg, 1994). Arrhenius (1998a) used $16 \%$, the value from the adult Atlantic herring model (Rudstam, 1988), for the proportion of assimilated ration egested by larval Atlantic herring. Both Kiørboe et al. (1987) and Limburg (1994) found the percent of food egested was $10 \%$ (by mass). However, Klumpp and von Westernhagen (1986) found egestion for Atlantic herring larvae ages 8-33 d averaged $17.6 \%$ (range: $13.4-25.6 \%$ ) of their ration. Based on the above three studies on larval and juvenile clupeids (Klumpp and von Westernhagen, 1986; Kiørboe et al., 1987; Limburg, 1994), we chose $12.5 \%$ as a first approximation for the proportion of consumption egested for an age- 0 herring, and $16 \%$ for age-1+ herring (Table 1).

Excretion (g prey g fish ${ }^{-1} \mathrm{~d}^{-1}$ ) was modeled as a constant proportion $\left(a_{\mathrm{E}}\right)$ of assimilation (consumption minus egestion):

$\mathrm{EX}_{\mathrm{i}}=a_{\mathrm{E}}\left(\mathrm{C}_{\mathrm{i}}-\mathrm{EG}_{\mathrm{i}}\right)$

Rudstam (1988) assumed excretion was 10\% of assimilation based on rates reported by Elliott (1976) for brown trout. Few studies on larval fish excretion have been conducted. For three species, Blennius pavo, plaice Pleuronectes platesssa, and Atlantic herring, Klumpp and von Westernhagen (1986) found the mean percent of the assimilated ration excreted was 6.0, 6.6 , and $10.7 \%$, respectively. Due to high mortality for Atlantic herring larvae in Klumpp and von Westernhagen's study (see Klumb, 2003), we used the average value of $7.8 \%$ as a first approximation of the percent of assimilation excreted by an age-0 herring, and assumed excretion for age-1+ herring was $10 \%$ (Table 1).

\subsubsection{Reproductive losses}

On the day of spawning (15 March), the average weight of an individual herring in each age class is reduced by $25 \%$ to account for gamete production. This value compares to Rudstam (1988) who used 15\%. Thus, EGG in Eq. (2.2.1.1) was set to $0.25 \times \mathrm{Kmat}_{\mathrm{i}}$ (values for maturities and percentage weight loss-Douglas Hay, pers. commun.). We multiply 0.25 by $\mathrm{Kmat}_{i}$ to account for the young ages when not all individuals in the age class are mature. For example, if $\mathrm{Kmat}_{i}$ is 0.4 then the weight loss due to spawning for the average individual in that age class is $40 \%$ of $25 \%$ loss because only $40 \%$ of the individuals are spawning.

\subsection{Multispecies feeding functional response}

A Type II functional response equation for multiple prey types (Rose et al., 1999) was used to compute daily consumption of each age $i$ herring $\left(C_{i}\right.$, g prey g fish $\left.{ }^{-1} d^{-1}\right)$, which was determined as sum of its consumption rates of each prey type $j$ :

$C_{i}=\sum_{j=1}^{3} C_{i j}$,

$C_{i j}=\frac{C_{\max }\left(\mathrm{PD}_{i j} v_{i j} / K_{i j}\right)}{1+\sum_{k=1}^{3}\left(\mathrm{PD}_{i k} v_{i k} / K_{i k}\right)}$,

where $C_{\max }$ is the maximum consumption rate (gpreygfish ${ }^{-1} \mathrm{~d}^{-1}$ ) of individual herring of age $i$ from Eq. (2.2.3.1), $\mathrm{PD}_{i j}$ the density of prey type $j\left(\mathrm{gprey} \mathrm{m}^{-3}\right)$ to age $i$ herring, $v_{i j}$ the vulnerability of prey type $j$ to age $i$ herring (dimensionless), and $K_{i j}$ is the half saturation constant (g prey $\mathrm{m}^{-3}$ ) for individual age $i$ herring feeding on prey type 
j. A total of three prey types generated by NEMURO were included in the current fish model: $\mathrm{ZS}(j=1), \mathrm{ZL}(j=2)$, and ZP $(j=3)$. In the vicinity of Vancouver Island, herring eat mainly copepod eggs as larvae, copepod adults and nauplii as juveniles, and euphausiids as adults (Hay et al., 2001). The three zooplankton groups in NEMURO represent functional groups based on prey size. We treated the ZS as including microzooplankton, ZL as including copepods, and ZP as representing euphausiids and chaetognaths. Densities of each of the three zooplankton types were calculated in NEMURO in $\mathrm{mol} \mathrm{Nl}^{-1}$, and are converted to gwetweight $\mathrm{m}^{-3}$ by multiplying by:

$$
\begin{aligned}
\mathrm{tt} 1 & =\frac{14 \mathrm{gN}}{\mathrm{mol} \mathrm{N}} \frac{1 \mathrm{gdry} \text { weight }}{0.07 \mathrm{gNdry} \text { weight }} \frac{1 \mathrm{~g} \text { wet weight }}{0.2 \mathrm{gdry} \text { weight }} \frac{10^{3} \mathrm{l}}{\mathrm{m}^{3}} \\
& =10^{-6} \text { g wet weight } \mathrm{m}^{-3}
\end{aligned}
$$

Vulnerabilities were specified to reflect roughly how diets of larger herring shift towards larger prey species, and the $K_{i j}$ parameters were determined by calibration (Table 1).

\subsection{Population dynamics model}

\subsubsection{Herring life cycle}

Southern British Columbia herring are comprised of the WCVI and the Strait of Georgia (SOG) stocks. We used information for the WCVI and SOG stocks in our herring application of NEMURO.FISH because adults of these two stocks commingle on their summer feeding grounds. Southern British Columbia herring spawn in early March in subtidal areas of sheltered inlets, sounds, and bays, with the WCVI and SOG stocks spawning in their respective spawning areas (Table 2). Adults of both stocks then leave their spawning grounds and commingle in their summer feeding grounds in the shelf waters (<200 m deep) off the west coast of Vancouver Island (roughly the La Perouse Bank area), where most of each year's growth occurs (Hay et al., 1988; Tanasichuk, 1997). Eggs adhere to vegetation and other hard substrates in the spawning areas, and after about 2-3 weeks eggs hatch into yolk-sac larvae; the yolksac larval stage lasts about 1 week. Larvae metamorphose into juveniles about 2-3 months after hatching (Lassuy, 1989). Juveniles remain inshore near their spawning areas, progressively moving into deeper nearshore waters, until the summer of their third year when juveniles from both stocks join the adults and move onto shelf waters. During every fall, adults move progressively inshore from their summer feeding grounds on the shelf until they reach their respective nearshore spawning grounds for spawning in March of the next year (Hay et al., 2001).

\subsubsection{Mortality}

The number of individuals in each of the ten age-classes is decremented daily based on annual mortality rate:

$$
\frac{d N_{i, y}}{d t}=-\left[M_{i}+F_{i}\right] N_{i, y},
$$

where $N_{i, y}$ is the number of herring (numbers $\mathrm{m}^{-3}$ ) in age class $i$ in year $y, M_{i}$ the instantaneous natural mortality (year ${ }^{-1}$ ), and $F_{i}$ is the instantaneous fishing mortality (year ${ }^{-1}$ ) on age class i. On 20 March of each year, just after spawning, surviving individuals are promoted to the next age-class, and a new number of age-0 individuals are specified. In the model, the first age class of herring corresponds to young-of-the-year (0-12 months), the second age class corresponds to age-1 herring (12-24 months), etc. Total biomass (TB, g wet weight $\mathrm{m}^{-2}$ ) at any given time is computed as

$\mathrm{TB}=\left[\sum_{i=1}^{10} \mathrm{~N}_{i} \mathrm{~W}_{\mathrm{i}}\right] \mathrm{MLD}$

where $N_{i}$ is the numbers of individuals in age class $i$ (number $\mathrm{m}^{-3}$ ) and $W_{i}$ average weight per individual in age class $i$ ( $g$ wet weight). Multiplying by the mixed layer depth (MLD, $\mathrm{m}$ ) converts g wet weight $\mathrm{m}^{-3}$ into g wet weight $\mathrm{m}^{-2}$. As a reasonable approximation, we used a constant mixed layer depth of $100 \mathrm{~m}$ to compute herring biomass.

\subsubsection{Recruitment}

Spawning biomass in year y is calculated on 15 March as

$\mathrm{SB}_{y}=\left[\sum_{i=1}^{10} \mathrm{~N}_{i, y} \mathrm{~W}_{i, y} \mathrm{Kmat}_{i}\right] 0.5 \times 10^{-9}\left(100.0 \times 21334.0 \times 10^{-6}\right)$

where $\mathrm{SB}_{y}$ is the spawning biomass in year $\mathrm{y}(1000 \mathrm{MT})$ and $\mathrm{Kmat}_{i}$ is the fraction mature of age $i$ herring (Hay et al., 1987). Spawning biomass is multiplied by 0.5 because only half of the spawning biomass goes to WCVI, with the other half going to the SOG. The remaining constants adjust for the volume of the modeled (i.e., feeding) area (100 $\mathrm{m}$ deep times $21334 \mathrm{~km}^{2}$ ) and convert SB to units of $1000 \mathrm{MT}$ (which is used in the spawner-recruit relationship) by multiplying by $10^{-9}$ ( $\mathrm{g}$ to $1000 \mathrm{MT}$ ) and by $10^{-6}\left(\mathrm{~m}^{2}\right.$ in a $\left.\mathrm{km}^{2}\right)$. With this formulation, spawning biomass is calculated as the biomass of fish present in the feeding area that will migrate to the spawning area.

Recruitment of herring, which introduces the new number of age- 0 individuals each year, was modeled in two ways: constant or dynamically using a spawner-recruit function. Recruitment in the model was defined as the number entering on 20 June of the same year of spawning (i.e., at about 3 months of age), and all new recruits started at a weight of $0.2 \mathrm{~g}$ wet weight. The number of recruits each year under constant recruitment was set to 155.1 number $\mathrm{m}^{-3}$. The constant recruitment value was determined as the average value predicted under the baseline simulation using the dynamic recruitment option. How we calibrated the dynamic recruitment version is described later in Section 3.

Constant recruitment was useful for some model analyses because predicted herring weight-at-age reached steady state over time, and for comparing herring effects on their prey dynamics. Inclusion of an environment-dependent spawner-recruit relationship was also useful because it permitted the reproduction of observed recruitment variation on annual and multi-decadal time scales, and allowed for closure of the life cycle (self-sustaining simulations) and investigation of regime shifts and climate variation effects on growth via their effects on recruitment. 
Table 2 - Schematic representation of the herring life cycle showing calendar months, age in months, life stages, typical weights and lengths of individuals, and general habitat information

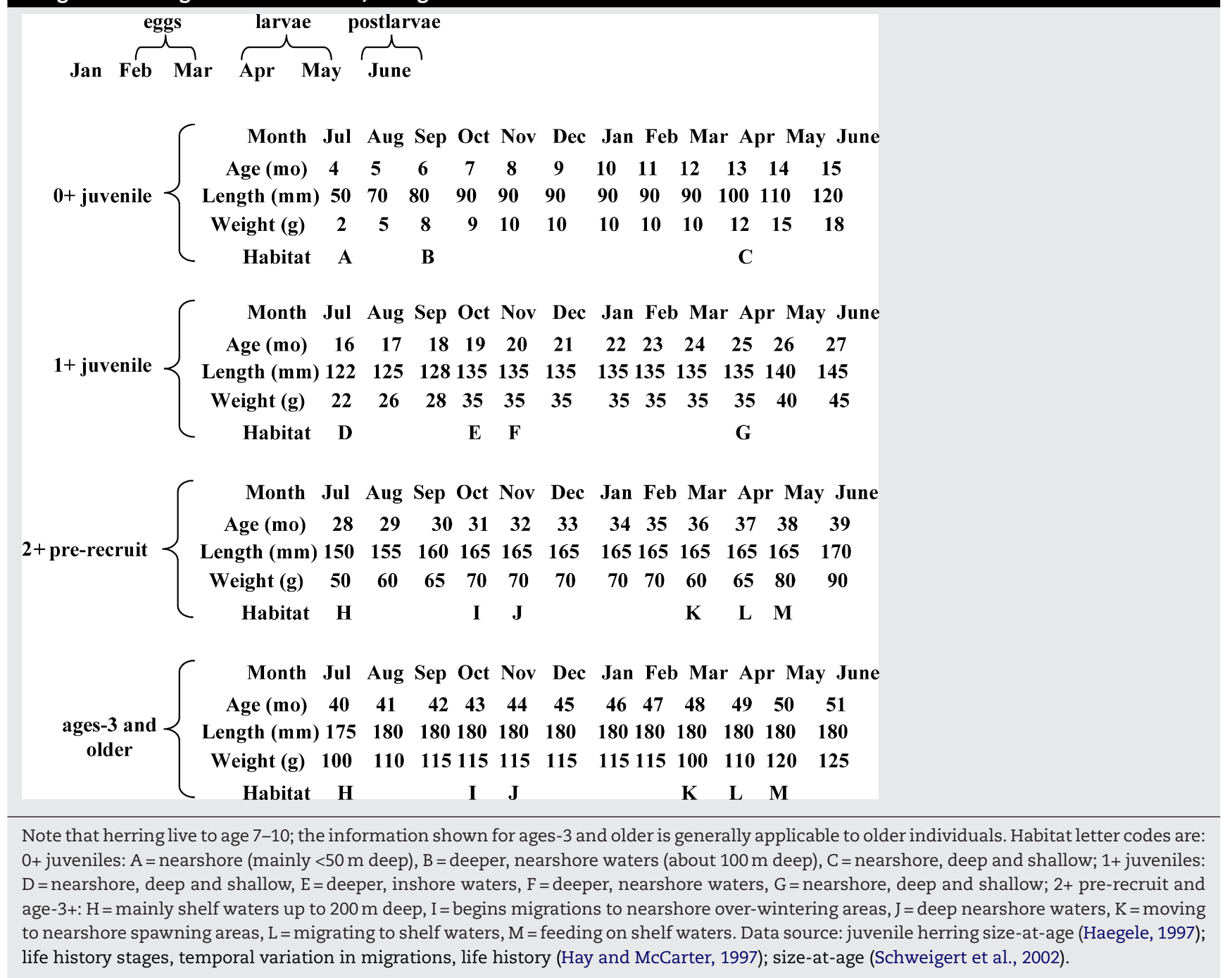

Dynamic recruitment was determined using an environment-dependent Ricker spawner-recruit model fitted to longterm data for WCVI herring (Williams and Quinn, 2000a,b; Rose et al., 2007b).

$\mathrm{N}_{3, y+3}=\mathrm{e}^{\left(3.27-0.031 \mathrm{SB}_{y}+0.258 \mathrm{NPPI}_{y}-0.193 \mathrm{AIR}_{y}-0.281 \mathrm{SST}_{y}\right)} \times 10^{-6} \times 10^{-9}$

where $N_{3, y+3}$ is the age-3 recruits 3 years later (numbersgspawningbiomass $\left.{ }^{-1}\right), \mathrm{SB}_{\mathrm{y}}$ the spawning biomass (1000 MT), NPPI $y$ is the North Pacific Pressure Index, $\mathrm{AIR}_{y}$ the air temperature, and $\mathrm{SST}_{\mathrm{y}}$ is the sea surface temperature in year $y$. NPPI, AIR, and SST are expressed as annual anomalies (Fig. 3). The coefficients at the end of Eq. (2.4.3.2) convert recruitment in millions of recruits per $1000 \mathrm{MT}$ of spawning biomass into recruit per gram of spawning biomass. The number of newly recruiting age- 0 individuals on 20 June was determined as the estimate of age- 3 recruits $\left(N_{3, y}\right)$ times the spawning biomass in year $y$ (expressed in gwet weight $\mathrm{m}^{-3}$ ), inflated by the survival occurring between roughly 6 months of age- 1 and age- 3 (elhm, fraction), and multiplied by 2 to reflect both WCVI and SOG returns.

$N_{1, y}=\frac{N_{3, y} \mathrm{SB}_{y} \times 2}{\text { elhm }}$.

\subsection{Dynamic linkage of fish and NEMURO models}

In NEMURO.FISH, the bioenergetics and NEMURO models are solved simultaneously. Zooplankton prey groups determine the consumption term of the fish bioenergetics model, and are, in turn, reduced by the amount eaten by the herring. Herring excretion is added to the ammonium pool of NEMURO, and herring egestion waste is added to the PON pool. NEMURO represents time in units of $\mathrm{s}$, while the fish model operates on daily rates. Linkages between the NEMURO and fish models therefore involved fish models rates expressed as annual or daily rates being converted into rates expressed in $s$ for the NEMURO.FISH system of differential equations. All differential equations were solved using a fourth-order Runge-Kutta numerical integration routine using a time step of $1 \mathrm{~d}$.

The total rates of predation of zooplankton and rates of excretion and egestion of nutrients $\left(\mathrm{g} \mathrm{m}^{-3} \mathrm{~d}^{-1}\right)$ were computed 


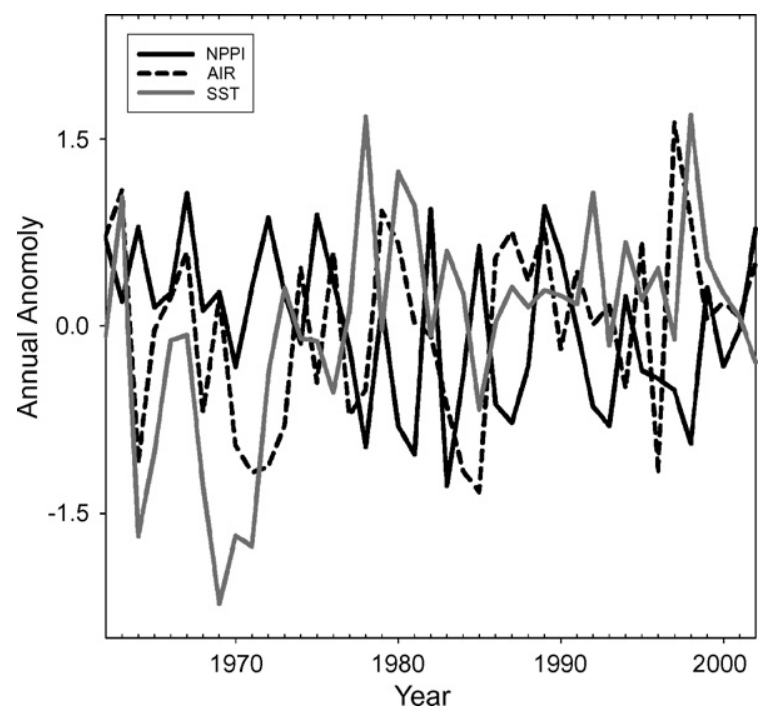

Fig. 3 - Historical annual anomalies of the three environmental variables (NPPI, SST, and AIR) used in the Ricker spawner-recruit relationship.

as

$\mathrm{ZS}_{\text {tot }}=\sum_{\mathrm{i}=1}^{10} \mathrm{C}_{\mathrm{i1}} \mathrm{W}_{\mathrm{i}} \mathrm{N}_{\mathrm{i}}$

$\mathrm{ZL}_{\text {tot }}=\sum_{\mathrm{i}=1}^{10} \mathrm{C}_{\mathrm{i} 2} \mathrm{~W}_{\mathrm{i}} \mathrm{N}_{\mathrm{i}}$

$\mathrm{ZP}_{\text {tot }}=\sum_{i=1}^{10} \mathrm{C}_{\mathrm{i} 3} \mathrm{~W}_{\mathrm{i}} \mathrm{N}_{\mathrm{i}}$

$\mathrm{EX}_{\mathrm{tot}}=\sum_{i=1}^{10} \mathrm{EX}_{\mathrm{i}} \mathrm{W}_{\mathrm{i}} \mathrm{N}_{\mathrm{i}}$

$\mathrm{EG}_{\text {tot }}=\sum_{i=1}^{10} \mathrm{EG}_{\mathrm{i}} \mathrm{W}_{\mathrm{i}} \mathrm{N}_{\mathrm{i}}$

where $C_{i, j}$ is the consumption rate of the ith age class of herring on the jth zooplankton group, $N_{i}$ and $W_{i}$ the numbers and average weight of individuals in the ith age-class, and $\mathrm{EX}_{i}$ and $E_{i}$ are the egestion and excretion rates. NEMURO state variable differential equations were modified to include loss or gain terms due to herring:

$$
\begin{aligned}
& \frac{\mathrm{dZS}}{\mathrm{dt}}=\frac{\mathrm{dZS}}{\mathrm{dt}}(\text { from NEMURO })-\frac{Z_{\text {tot }}}{\mathrm{tt} 1 \times \mathrm{d} 2 \mathrm{~s}}, \\
& \frac{\mathrm{dZL}}{\mathrm{dt}}=\frac{\mathrm{dZL}}{\mathrm{dt}}(\text { from NEMURO })-\frac{\mathrm{ZL}_{\mathrm{tot}}}{\mathrm{tt} 1 \times \mathrm{d} 2 \mathrm{~s}}, \\
& \frac{\mathrm{dZP}}{\mathrm{dt}}=\frac{\mathrm{dZP}}{\mathrm{dt}}(\text { from NEMURO })-\frac{\mathrm{ZP}_{\mathrm{tot}}}{\mathrm{tt} 1 \times \mathrm{d} 2 \mathrm{~s}},
\end{aligned}
$$

$$
\begin{aligned}
& \frac{\mathrm{dNH}_{4}}{\mathrm{dt}}=\frac{\mathrm{dNH}_{4}}{\mathrm{dt}}(\text { from NEMURO })+\frac{\mathrm{EX}_{\text {tot }}}{\mathrm{tt} 1 \times \mathrm{d} 2 \mathrm{~s}}, \\
& \frac{\mathrm{dPON}}{\mathrm{dt}}=\frac{\mathrm{dPON}}{\mathrm{dt}}(\text { from NEMURO })+\frac{\mathrm{EG}_{\mathrm{tot}}}{\mathrm{tt} 1 \times \mathrm{d} 2 \mathrm{~s}},
\end{aligned}
$$

where d2s is $86400 \mathrm{~s} \mathrm{~d}^{-1}$, and tt1 (Eq. (2.3.3)) converts mol N $\mathrm{l}^{-1}$ to gwetweight $\mathrm{m}^{-3}$. Since it appears in the denominator of the right hand term in Eqs. (2.5.6)-(2.5.10) it converts gwet weight $\mathrm{m}^{-3}$ in the fish model to the NEMURO units of mol Nl-1.

\subsection{Application NEMURO to WCVI}

NEMURO, uncoupled from the herring bioenergetics model, was calibrated to monthly field data on nutrients, phytoplankton, and zooplankton densities collected in the WCVI and California Current ecosystems (Rose et al., 2007a).

Solar radiation data were collected from $49^{\circ} \mathrm{N}$ latitude and, based on idealized equations relating light to latitude, we estimated that maximum total light for the area off the West Coast of Vancouver Island $\left(\sim 49^{\circ} \mathrm{N}\right.$ latitude) is around $1000 \mathrm{~W} \mathrm{~m}^{-2}$ but varies seasonally. If we assume that the amount of radiation in the 400-700 $\mathrm{nm}$ wavelength, or photosynthetically available radiation (PAR), was $40 \%$ of the solar radiation at the sea surface (Apel, 1987), then we would expect PAR at $49^{\circ} \mathrm{N}$ to be around $400 \mathrm{~W} \mathrm{~m}^{-2}$. We took 2 years of light data from 3DNEMURO ( $\mathrm{W} \mathrm{m}^{-2}$ ) (Aita et al., 2006), averaged by Julian Day then converted to units of ly $\mathrm{min}^{-1}$ by multiplying $\mathrm{W} \mathrm{m}^{-2}$ by 0.001433 ( 1 ly $\mathrm{min}^{-1}=698 \mathrm{~W} \mathrm{~m}^{-2}$ ), and fitting a sinusoid to the data. The 3D-NEMURO data were based on light data from the NCEP/NCAR (National Centers for Environmental Prediction, NOAA National Weather Service, and National Center for Atmospheric Research) reanalysis data set. A sinusoid was fit to the data with nonlinear regression. The equation describing seasonal solar radiation was

$L=0.0357+\left(0.2502 \times 0.5\left(1-\cos \left(\frac{2 \pi(\mathrm{JDAY}+7)}{365}\right)\right)\right)$,

where JDAY is Julian day and $L$ is light ly $\min ^{-1}$. The trigonometric function that relates day of year to daily solar radiation and the observed data are given in Fig. 4.

Daily surface water temperature measurements were taken from the Amphitrite Lighthouse off the west coast of Vancouver Island $\left(48^{\circ} 55^{\prime} \mathrm{N}, 125^{\circ} 32^{\prime} \mathrm{W}\right)$. A sinusoid describing seasonal water temperature:

$\operatorname{TEMP}=5.0+\left(9.0 \times 0.5\left(1-\cos \left(\frac{2 \pi(\mathrm{JDAY}-90)}{365}\right)\right)\right)$

was fit to the data using nonlinear regression, where JDAY is the Julian day and TEMP is the surface water temperature $\left({ }^{\circ} \mathrm{C}\right)$. Observed data and the fit curve are given in Fig. 5.

Mixed layer depth was specified as piece-wise linear function of day of year. Rose et al. (2007a) used both ad hoc (fit-by-eye) and automated (optimization) calibration to determine a set of NEMURO parameter values (Table 3 ) that best 


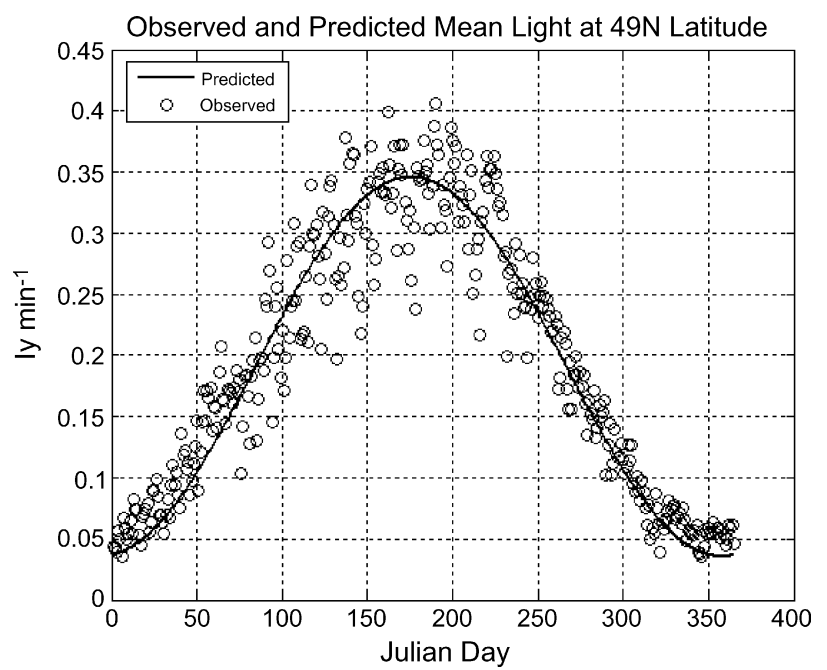

Fig. 4 - Observed and predicted daily incident light for West Coast of Vancouver Island (used as a driving variable for the NEMURO model).

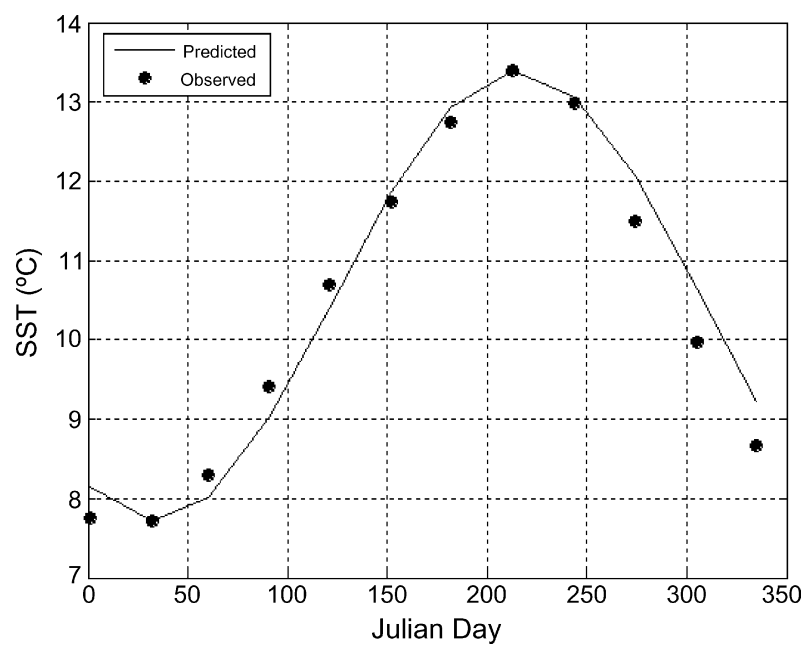

Fig. 5 - Observed and predicted mean sea surface temperature at Amphitrite Lighthouse $\left(48^{\circ} 55^{\prime} \mathrm{N}, 125^{\circ} 32^{\prime} \mathrm{W}\right)$ (used as a driving variable for the NEMURO model).

reproduced the monthly averaged field data over a typical year.

\section{Model simulations}

NEMURO.FISH was run for 30 years using repeated environmental conditions (solar radiation, temperature, mixed layer depth) for NEMURO and using either constant or dynamic herring recruitment. Calibration of the herring model used dynamic recruitment and $K_{i j}$ parameters of the multispecies functional response and the early life history survival rate $(\mathrm{elhm})$ were adjusted until herring dynamics satisfied three constraints that were based on historical WCVI data:
(1) the total herring biomass had to be between 2 and 5 gwet weight $\mathrm{m}^{-2}$, (2) the maximum weight of an adult herring was about 200 g wet weight ind $^{-1}$, and (3) there had to be good agreement between observed and predicted herring weight-at-age (gww) over all age groups. We did not adjust the NEMURO parameters from their previously calibrated values (Rose et al., 2007a). Since NEMURO.FISH was run with no interannual variation in environmental conditions, we did not see the need to allow NEMURO to spin-up before dynamically coupling the two models. Thus, the models were dynamically couple from the very beginning of the simulation.

In an earlier exploration of NEMURO.FISH dynamics (Rose et al., 2004), we performed two simulations under constant recruitment with and without herring affecting NEMURO dynamics (i.e., coupled versus uncoupled). Running NEMURO.FISH uncoupled eliminated the effects of herring consumption on zooplankton and of herring excretion and egestion on nutrient dynamics. Constant recruitment was used to make comparison of the two simulations easier. Under dynamic recruitment, herring affects on NEMURO dynamics would influence herring spawning biomass, which in turn would affect recruitment and subsequent herring biomass and therefore NEMURO dynamics. Comparison of simulated zooplankton and nutrient densities between coupled and uncoupled simulations with constant recruitment permits determination of the degree of influence herring have on their prey and on nutrient recycling.

\section{Uncertainty analysis}

We performed a Monte Carlo uncertainty analysis of the herring version of the NEMURO.FISH model using Latin Hypercube sampling (McKay et al., 1979; Rose et al., 1999). Monte Carlo uncertainty analysis allows parameters to be varied together, rather than one-at-a-time in the traditional approach to sensitivity analysis. Probability distributions are assigned to model parameters, and multiple simulations are performed using repeated sampling of parameter values from their distributions. Latin hypercube sampling uses a stratified sampling approach to each parameter distribution to ensure adequate coverage of the range of parameter values with relatively fewer simulations. Correlation analysis is then applied relating predicted output variables to parameter values over the simulations. The premise is that the greater the correlation between a parameter and the predicted variable (\% variance explained in the output variable by the input parameter), the more influence that parameter has in controlling model behavior (Rose et al., 1991).

Three sets of uncertainty analyses were performed under dynamic recruitment, with each consisting of 300 30-year model simulations. All parameters were assigned normal probability distributions with means set to their calibration values and standard deviations set so that their coefficient of variation (CV) was $1 \%$. Thirty-seven of the possible 115 fish parameters were held constant for all three sets of simulations; thus, 78 fish-related parameters were allowed to vary. The 37 parameters held constant were the temperature effects on consumption, three fishing mortalities for unexploited age groups $\left(F_{1}, F_{2}\right.$, and $\left.F_{3}\right)$, and all ten maturity 
Table 3 - Parameters calibrated to the West Coast Vancouver Island version of the NEMURO lower trophic level model

\begin{tabular}{|c|c|c|c|}
\hline Parameter & Description & Value & Units \\
\hline \multicolumn{4}{|c|}{ Small phytoplankton (PS) } \\
\hline$I_{\text {opts }}$ & Optimum light intensity & 0.15 & ly $\min ^{-1}$ \\
\hline$V_{\operatorname{maxs}}$ & Maximum photosynthetic rate at $0^{\circ} \mathrm{C}$ & $5.629629 \mathrm{E}-06$ & $\mathrm{~s}^{-1}$ \\
\hline $\mathrm{K}_{\mathrm{NO} 3 \mathrm{~S}}$ & Half saturation constant for $\mathrm{NO}_{3}$ & $1.0 \mathrm{E}-06$ & $\operatorname{molNl} l^{-1}$ \\
\hline $\mathrm{K}_{\mathrm{NH} 4 \mathrm{~S}}$ & Half saturation constant for $\mathrm{NH}_{4}$ & $0.1 \mathrm{E}-06$ & $\mathrm{molNl} l^{-1}$ \\
\hline$\Psi \mathrm{s}$ & $\mathrm{NH}_{4}$ inhibition coefficient & $1.5 e+06$ & $\mathrm{molN}^{-1}$ \\
\hline$k_{\mathrm{GppS}}$ & Temperature coefficient for photosynthetic rate & 0.0693 & ${ }^{\circ} \mathrm{C}^{-1}$ \\
\hline$M_{\text {orPSO }}$ & Mortality rate at $0^{\circ} \mathrm{C}$ & 0.67708 & $\left(\mathrm{molNl}^{-1}\right)^{-1} \mathrm{~s}^{-1}$ \\
\hline$k_{\text {MorPS }}$ & Temperature coefficient for mortality & 0.0693 & ${ }^{\circ} \mathrm{C}^{-1}$ \\
\hline$R_{\text {esPSO }}$ & Respiration rate at $0^{\circ} \mathrm{C}$ & $3.4722 \mathrm{E}-07$ & $\mathrm{~s}^{-1}$ \\
\hline$k_{\text {ResPS }}$ & Temperature coefficient for respiration & 0.0693 & ${ }^{\circ} \mathrm{C}^{-1}$ \\
\hline$\gamma_{\mathrm{S}}$ & Ratio of extracellular excretion to photosynthesis & 0.135 & \\
\hline \multicolumn{4}{|c|}{ Large phytoplankton (PL) } \\
\hline$I_{\text {optL }}$ & Optimum light intensity & 0.15 & ly $\min ^{-1}$ \\
\hline$V_{\operatorname{maxL}}$ & Maximum photosynthetic rate at $0^{\circ} \mathrm{C}$ & $8.259259 \mathrm{E}-6$ & $\mathrm{~s}^{-1}$ \\
\hline $\mathrm{K}_{\mathrm{NO} \mathrm{L} \mathrm{L}}$ & Half saturation constant for $\mathrm{NO}_{3}$ & $3.0 \mathrm{E}-06$ & $\operatorname{molNl} l^{-1}$ \\
\hline $\mathrm{K}_{\mathrm{NH} 4 \mathrm{~L}}$ & Half saturation constant for $\mathrm{NH}_{4}$ & $0.3 \mathrm{E}-06$ & $\mathrm{molNl}^{-1}$ \\
\hline $\mathrm{K}_{\mathrm{SiL}}$ & Half saturation constant for $\mathrm{Si}$ & $6.0 \mathrm{E}-06$ & $\operatorname{molsil}{ }^{-1}$ \\
\hline$\Psi_{\mathrm{L}}$ & $\mathrm{NH}_{4}$ inhibition coefficient & $1.5 \mathrm{E}+06$ & $\mathrm{molN}^{-1}$ \\
\hline$k_{\mathrm{GppL}}$ & Temperature coefficient for photosynthetic rate & 0.0693 & ${ }^{\circ} \mathrm{C}^{-1}$ \\
\hline$M_{\text {orPLO }}$ & Mortality rate at $0^{\circ} \mathrm{C}$ & 0.3356 & $\left(\mathrm{molNl}^{-1}\right)^{-1} \mathrm{~s}^{-1}$ \\
\hline$k_{\text {MorPL }}$ & Temperature coefficient for mortality & 0.0693 & ${ }^{\circ} \mathrm{C}^{-1}$ \\
\hline$R_{\text {esPLO }}$ & Respiration rate at $0^{\circ} \mathrm{C}$ & $3.472222 \mathrm{E}-07$ & $\mathrm{~s}^{-1}$ \\
\hline$k_{\text {ResPL }}$ & Temperature coefficient for respiration & 0.0693 & ${ }^{\circ} \mathrm{C}^{-1}$ \\
\hline$\gamma_{\mathrm{L}}$ & Ratio of extracellular excretion to photosynthesis & 0.135 & \\
\hline \multicolumn{4}{|c|}{ Small zooplankton (ZS) } \\
\hline $\mathrm{GR}_{\operatorname{maxSps}}$ & Maximum rate of grazing PS at $0^{\circ} \mathrm{C}$ & $3.62962 \mathrm{E}-06$ & $\mathrm{~s}^{-1}$ \\
\hline$k_{\text {GraS }}$ & Temperature coefficient for grazing & 0.0693 & ${ }^{\circ} \mathrm{C}^{-1}$ \\
\hline$\lambda_{S}$ & Ivlev constant & $0.4 \mathrm{E}+06$ & $\left(\mathrm{molNl} l^{-1}\right)^{-1}$ \\
\hline PS2ZS* $^{*}$ & Threshold value for grazing PS & $0.043 \mathrm{E}-06$ & $\operatorname{molNl} l^{-1}$ \\
\hline Alphazs & Assimilation efficiency & 0.7 & \\
\hline Betazs & Growth efficiency & 0.3 & \\
\hline$M_{\text {orzso }}$ & Mortality rate at $0^{\circ} \mathrm{C}$ & 0.877 & $\left(\mathrm{~mol} \mathrm{Nl} l^{-1}\right)^{-1} \mathrm{~s}^{-1}$ \\
\hline$k_{\text {Morzs }}$ & Temperature coefficient for mortality & 0.1099 & ${ }^{\circ} \mathrm{C}^{-1}$ \\
\hline \multicolumn{4}{|c|}{ Large zooplankton (ZL) } \\
\hline $\mathrm{GR}_{\operatorname{maxLps}}$ & Maximum rate of grazing PS at $0^{\circ} \mathrm{C}$ & 1.157E-06 & $\mathrm{s}^{-1}$ \\
\hline $\mathrm{GR}_{\operatorname{maxLpl}}$ & Maximum rate of grazing PL at $0^{\circ} \mathrm{C}$ & $2.6296 \mathrm{E}-06$ & $\mathrm{~s}^{-1}$ \\
\hline $\mathrm{GR}_{\operatorname{maxLzs}}$ & Maximum rate of grazing $\mathrm{ZS}$ at $0^{\circ} \mathrm{C}$ & $1.6296 \mathrm{E}-06$ & $\mathrm{~s}^{-1}$ \\
\hline$k_{\mathrm{GraL}}$ & Temperature coefficient for grazing/predation & 0.0693 & ${ }^{\circ} \mathrm{C}^{-1}$ \\
\hline$\lambda_{\mathrm{L}}$ & Ivlev constant & $1.4 \mathrm{e}+06$ & $\left(\mathrm{~mol} \mathrm{Nl} l^{-1}\right)^{-1}$ \\
\hline PS2ZL* & Threshold value for grazing PS & $4.0 \mathrm{E}-08$ & $\mathrm{molNl} \mathrm{N}^{-1}$ \\
\hline PL2ZL* & Threshold value for grazing PL & $4.0 \mathrm{E}-08$ & $\mathrm{molNl}^{-1}$ \\
\hline $\mathrm{ZS} 2 \mathrm{ZL}^{*}$ & Threshold value for grazing ZS & $4.0 \mathrm{E}-08$ & $\operatorname{molNl} 1^{-1}$ \\
\hline Alpha $_{\mathrm{ZL}}$ & Assimilation efficiency & 0.7 & \\
\hline BetazL & Growth efficiency & 0.3 & \\
\hline$M_{\text {orZLO }}$ & Mortality rate at $0^{\circ} \mathrm{C}$ & 0.877 & $\left(\mathrm{molNl}^{-1}\right)^{-1} \mathrm{~s}^{-1}$ \\
\hline$k_{\text {MorzL }}$ & Temperature coefficient for mortality & 0.1099 & ${ }^{\circ} \mathrm{C}^{-1}$ \\
\hline \multicolumn{4}{|c|}{ Predatory zooplankton (ZP) } \\
\hline $\mathrm{GR}_{\operatorname{maxPpl}}$ & Maximum rate of grazing PL at $0^{\circ} \mathrm{C}$ & $1.3148 \mathrm{E}-06$ & $\mathrm{~s}^{-1}$ \\
\hline $\mathrm{GR}_{\operatorname{maxPzs}}$ & Maximum rate of grazing $\mathrm{ZS}$ at $0^{\circ} \mathrm{C}$ & $1.3148 \mathrm{E}-06$ & $\mathrm{~s}^{-1}$ \\
\hline $\mathrm{GR}_{\operatorname{maxPzl}}$ & Maximum rate of grazing $\mathrm{ZL}$ at $0^{\circ} \mathrm{C}$ & $2.3148 \mathrm{E}-06$ & $\mathrm{~s}^{-1}$ \\
\hline$k_{\text {GraP }}$ & Temperature coefficient for grazing/predation & 0.0693 & ${ }^{\circ} \mathrm{C}^{-1}$ \\
\hline$\lambda_{\mathrm{P}}$ & Ivlev constant & $1.4 e+06$ & $\left(\mathrm{~mol} \mathrm{Nl} l^{-1}\right)^{-1}$ \\
\hline PL2ZP* & Threshold value for grazing PL & $4.0 \mathrm{E}-08$ & $\mathrm{molNl} \mathrm{N}^{-1}$ \\
\hline $\mathrm{ZS} 2 \mathrm{ZP}^{*}$ & Threshold value for grazing ZS & $4.0 \mathrm{E}-08$ & $\mathrm{molNl}^{-1}$ \\
\hline $\mathrm{ZL}^{2} \mathrm{ZP}^{*}$ & Threshold value for grazing ZL & $4.0 \mathrm{E}-08$ & $\mathrm{molNl}^{-1}$ \\
\hline$\Psi_{\mathrm{PL}}$ & Preference coefficient for PL & $4.605 e+06$ & $\left(\mathrm{molNl}^{-1}\right)^{-1}$ \\
\hline$\Psi_{\mathrm{zS}}$ & Preference coefficient for ZS & $3.01 e+06$ & $\left(\mathrm{~mol} \mathrm{Nl} l^{-1}\right)^{-1}$ \\
\hline Alpha $_{\mathrm{ZP}}$ & Assimilation efficiency & 0.7 & \\
\hline Beta $_{\mathrm{ZP}}$ & Growth efficiency & 0.3 & \\
\hline$M_{\text {orZPo }}$ & Mortality rate at $0^{\circ} \mathrm{C}$ & 0.877 & $\left(\mathrm{molNl}^{-1}\right)^{-1} \mathrm{~s}^{-1}$ \\
\hline$k_{\text {MorZP }}$ & Temperature coefficient for mortality & 0.1099 & ${ }^{\circ} \mathrm{C}^{-1}$ \\
\hline
\end{tabular}


Table 3 (Continued)

\begin{tabular}{|c|c|c|c|}
\hline Parameter & Description & Value & Units \\
\hline \multicolumn{4}{|l|}{ Nitrification } \\
\hline $\mathrm{N}_{\mathrm{it0}}$ & Nitrification rate at $0^{\circ} \mathrm{C}$ & $0.34722 \mathrm{E}-06$ & $\mathrm{~s}^{-1}$ \\
\hline$k_{\mathrm{Nit}}$ & Temperature coefficient for nitrification & 0.0693 & ${ }^{\circ} \mathrm{C}^{-1}$ \\
\hline \multicolumn{4}{|c|}{ Decomposition } \\
\hline setVP & PON sinking velocity & $4.6296 \mathrm{E}-04$ & $\mathrm{~ms}^{-1}$ \\
\hline VP2D 0 & Decomposition rate of $\mathrm{PON}$ to $\mathrm{DON}$ at $0^{\circ} \mathrm{C}$ & $1.1574 \mathrm{E}-06$ & $\mathrm{~s}^{-1}$ \\
\hline$k_{\mathrm{P} 2 \mathrm{D}}$ & Temperature coefficient for PON decomposition to DON & 0.0693 & ${ }^{\circ} \mathrm{C}^{-1}$ \\
\hline VP2 $\mathrm{N}_{0}$ & Decomposition rate of $\mathrm{PON}$ to $\mathrm{NH}_{4}$ at $0^{\circ} \mathrm{C}$ & $1.1574 \mathrm{E}-06$ & $\mathrm{~s}^{-1}$ \\
\hline$k_{\mathrm{P} 2 \mathrm{~N}}$ & Temperature coefficient for PON decomposition to $\mathrm{NH}_{4}$ & 0.0693 & ${ }^{\circ} \mathrm{C}^{-1}$ \\
\hline VD2 $\mathrm{N}_{0}$ & Decomposition rate of $\mathrm{DON}$ to $\mathrm{NH}_{4}$ at $0^{\circ} \mathrm{C}$ & $2.3148 \mathrm{E}-06$ & $\mathrm{~s}^{-1}$ \\
\hline$k_{\mathrm{D} 2 \mathrm{~N}}$ & Temperature coefficient for DON decomposition to $\mathrm{NH}_{4}$ & 0.0693 & ${ }^{\circ} \mathrm{C}^{-1}$ \\
\hline setVo & Opal sinking velocity & $4.6296 \mathrm{E}-04$ & $\mathrm{~ms}^{-1}$ \\
\hline VP2Si ${ }_{0}$ & Decomposition rate of Opal to silicate at $0^{\circ} \mathrm{C}$ & $1.1574 \mathrm{E}-06$ & $\mathrm{~s}^{-1}$ \\
\hline$k_{\mathrm{P} 2 \mathrm{Si}}$ & Temperature coefficient for Opal decomposition & 0.0693 & ${ }^{\circ} \mathrm{C}^{-1}$ \\
\hline \multicolumn{4}{|c|}{ Miscellaneous } \\
\hline$\alpha_{1}$ & Light extinction coefficient of sea water & 0.04 & $\mathrm{~m}^{-1}$ \\
\hline$\alpha_{2}$ & Self-shading coefficient for PS + PL & $4.0 \mathrm{E}+04$ & $(\mathrm{molN})^{-1} \mathrm{~m}^{-1}$ \\
\hline LLN & Number of sublayers for light calculations & 100 & \\
\hline RSiNPL & Si:N ratio of PL & 2.0 & mol Si mol N ${ }^{-1}$ \\
\hline RSiNZL & Si:N ratio of $\mathrm{ZL}$ and $\mathrm{ZP}$ & 2.0 & $\mathrm{~mol} \mathrm{Si} \mathrm{mol} \mathrm{N}{ }^{-1}$ \\
\hline RCN & C:N ratio & 6.625 & $\mathrm{~mol} \mathrm{C} \mathrm{mol} \mathrm{N}-1$ \\
\hline $\mathrm{TNO}_{\mathrm{d}}$ & Nitrate concentration in the deep layer & $25.0 \mathrm{E}-06$ & $\mathrm{molNl} l^{-1}$ \\
\hline $\mathrm{SiOH}_{d}$ & Silicate concentration in the deep layer & $35.0 \mathrm{E}-06$ & $\mathrm{~mol} \mathrm{Sil}^{-1}$ \\
\hline
\end{tabular}

Values in bold are calibrated values that differ from those reported in Kishi et al. (2007).

parameters. These were selected because the 24 parameters in Eqs. (2.2.4.1)-(2.2.4.9), if allowed to become random variables, could cause the log terms in Eqs. (2.2.4.3) and (2.2.4.6) to generate improper mathematical expressions. This situation generated fatal errors causing model execution to terminate prematurely. Three $F$ values from the unexploited age groups were forced to be zero to retain conditions known to take place in the commercial fishery (i.e., they are never exploited). Finally, the 10 maturity parameters, if they were allowed to be random variables, could reach biologically unrealistic values (i.e., values less than zero for younger ages and values greater than one for older ages). In the first set of 300 simulations (labeled LTL), just the 75 NEMURO parameters were varied and the 78 fish model parameters were held constant. In the second set of simulations (labeled FISH), all 75 NEMURO parameters were held constant and the 78 fish related parameter were allowed to vary. In the third set of simulations (labeled ALL), all 153 (75 NEMURO and 78 fish) parameters were allowed to vary. Correlations were examined for two contrasting years in the 30-year simulation: year 23 that had high herring biomass and low prey biomass and for year 3 that had low herring biomass and high prey biomass. Peak herring biomass was 7.506 g wet weight $\mathrm{m}^{-2}$ in year 23 versus

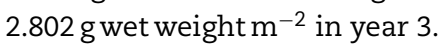

In order to perform the sensitivity analysis we needed to choose (and our choice was arbitrarily) a few model output variables to assess sensitivity. To keep things simple we chose only two. We chose herring weight-at-age 5 since a 5 -year old was in the middle of the herring life span. We also chose total population biomass (gwetweight $\mathrm{m}^{-2}$ ) on day 80 with the rational that total biomass would be a good integrator of sensitivities across all age groups in the population.

\section{Results}

\subsection{Calibration}

In comparison to the three constrains described in Section 3, daily total biomass and herring weights by age class (output on JDAY $=80$ each year) exhibited reasonable dynamics over the 30-year dynamic recruitment simulation (Fig. 6a and b). Predicted herring growth was similar to the observed weight over time of the 1972 cohort (Fig. 6c). The previously calibrated values for NEMURO are shown in Table 3, and the final parameter values for the herring model are given in Table 1 . We followed a single herring cohort over years to compare to the 1972 cohort. The 1972 cohort, from the historical catch-at-age data (age-0 in 1972, age-1 in 1973, etc.), was selected because it contained the most size-at-age observations spanning 10 calendar years.

\subsection{Coupled versus uncoupled simulations}

By year 10, predicted herring mean weight-at-age was lower in the coupled simulation than in the uncoupled simulation (Fig. 7). In the uncoupled constant recruitment assumption run (Fig. 7a), herring continued to grow throughout the simulation until steady state was eventually achieved. Maximum weight-at-age for the oldest age group was approximately $200 \mathrm{~g}$ and was consistent with observed data. In the coupled constant recruitment assumption run (Fig. 7b), herring consumption appeared as a mortality term on zooplankton prey abundance. The mortality terms were greater than the production terms and the prey abundance decreased. Conse- 

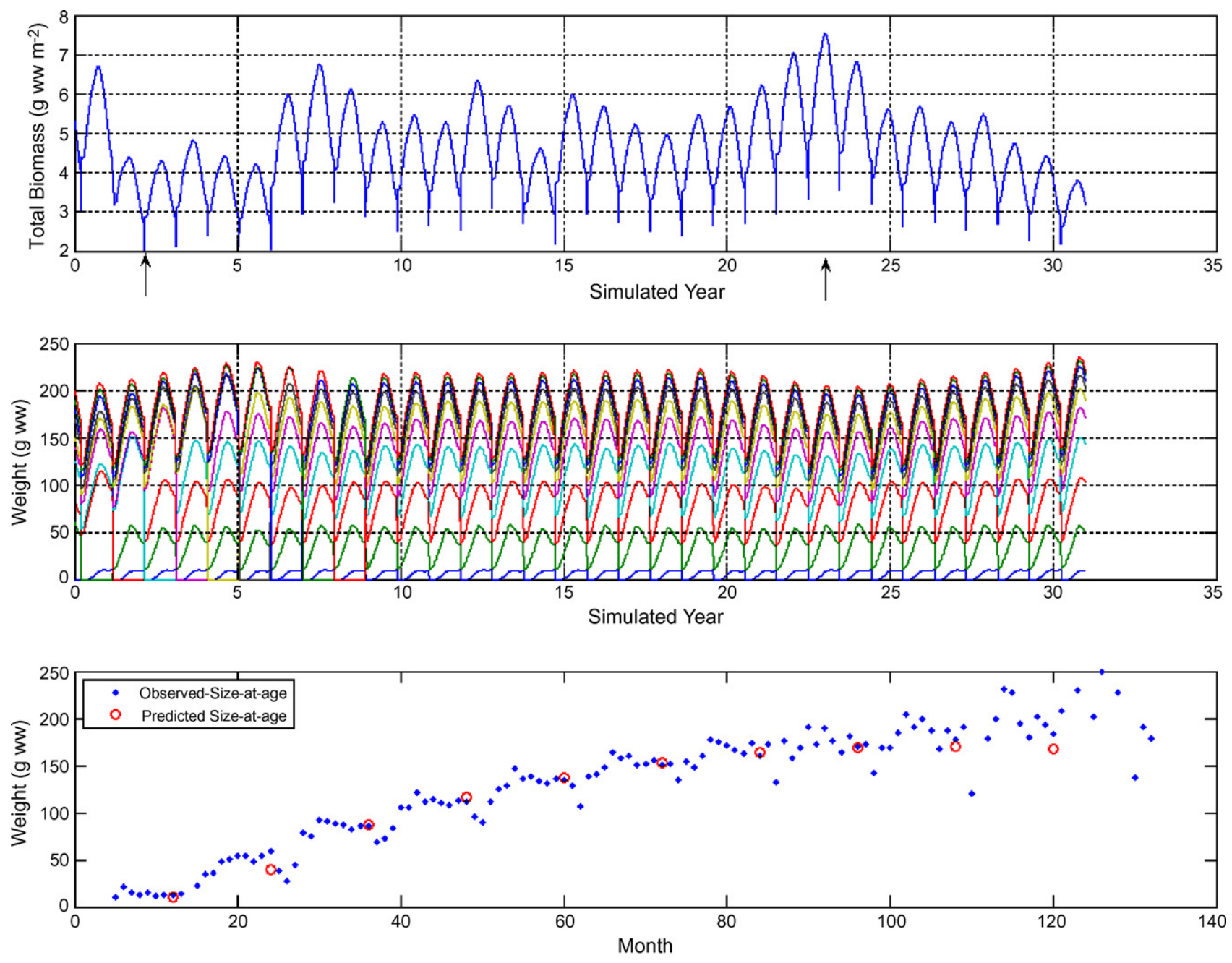

Fig. 6 - Dynamic results showing total biomass (top panel), individual weight for the 10 age groups carried in the population dynamics model (middle panel), and the correspondence between observed and predicted herring size-at-age (bottom panel). Arrows on the top panel show the contrasting years used for the Monte Carlo uncertainty analysis. The legend for the middle panel is located at the bottom of the figure.

quently herring growth rate decreased as they consumed their food resource and the overall trend between the two simulations are quite different-increasing in the uncoupled run and decreasing in the coupled run.

Herring had little impact on ZS (Fig. 8a) and mostly affected ZL (Fig. 8b) and ZP (Fig. 8c), causing lower densities in ZL and $\mathrm{ZP}$ in the coupled run. From the simulations performed, it cannot be determined from Figs. 7 and 8 if the results in Fig. 8b and $c$ are mainly from the direct influence of consumption on ZL and ZP. The decrease in ZP could be an indirect consequence of a decrease in its prey (ZL) from direct herring consumption. It is also possible that the decrease in ZP could be due to a combination of indirect loss of ZPs main food resource (i.e., $\mathrm{ZL}$ ) and herring consumption directed at $\mathrm{ZP}$. In either case, it is clear that including herring consumption as a dynamic mortality term on the zooplankton resulted in a density-dependent feedback and lower herring growth rates in the coupled simulation.
The effects of including the feedbacks were also apparent in the predicted dynamics of the LTLs. Predicted densities of ZL over time were generally lower under the coupled simulation than under the uncoupled simulation (Fig. 8b). Much smaller effects of herring consumption were predicted for ZS and ZP (Fig. 8a and C), because ZL was the dominant prey in the diet of simulated herring. The effects of herring excretion on ammonia and the effects of egestion on PON were both relatively small (Fig. 9a and b). Interestingly, the variation in the zooplankton densities in the coupled simulation caused by herring selectively consuming ZL cascaded downward in the food web resulting in consistent (albeit small) increases in PL density (Fig. 9c).

\subsection{Uncertainty analysis}

When NEMURO parameters were held constant and only fishrelated parameters were varied (top row of Fig. 10, labeled 

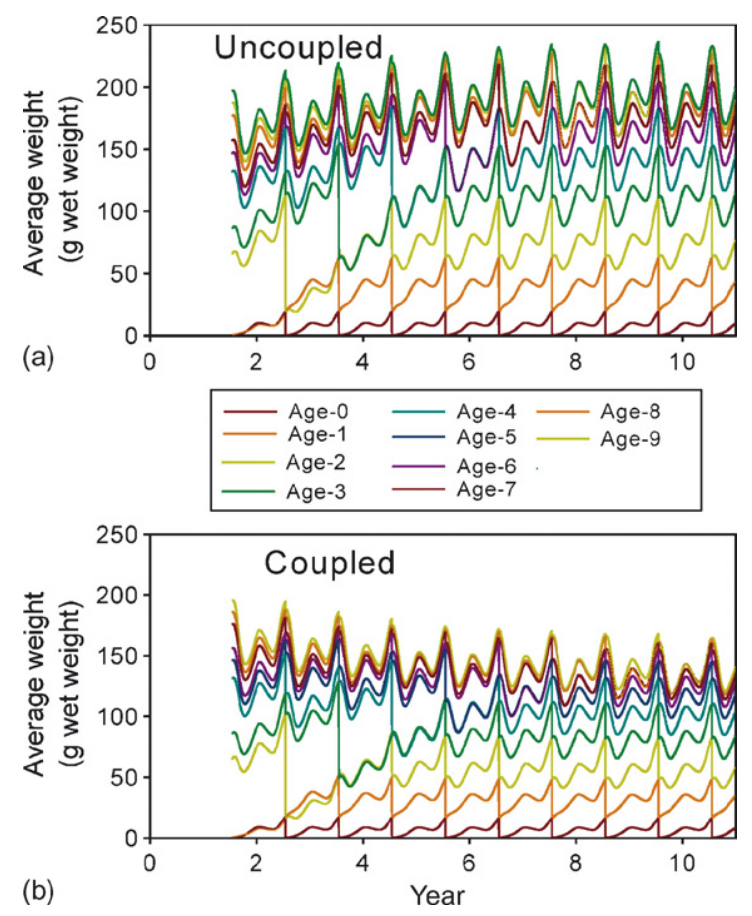

Fig. 7 - Predicted daily average weights per individual by age class of herring from (a) uncoupled and (b) coupled simulations of the NEMURO.FISH model (from Rose et al., 2004, Fig. 4.2).
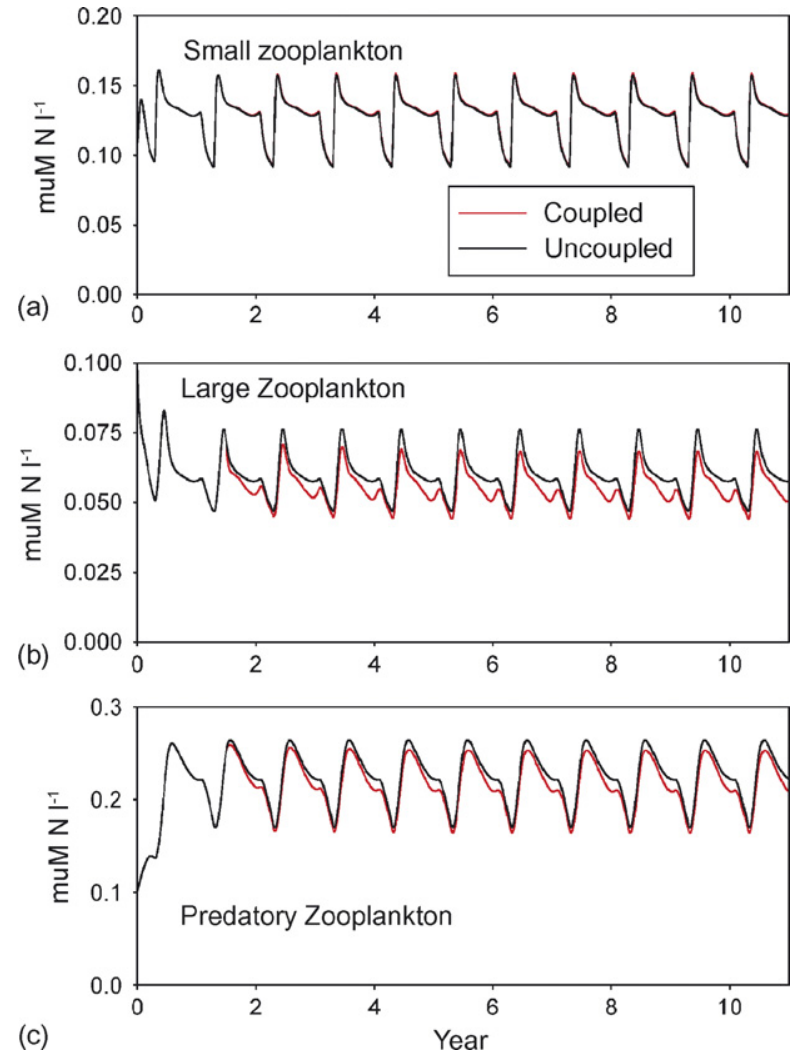

Fig. 8 - Predicted lower trophic level response of small zooplankton (a), large zooplankton (b), and predatory zooplankton (c) from uncoupled and coupled simulations of the NEMURO.FISH model (from Rose et al., 2004, Fig. 4.4).
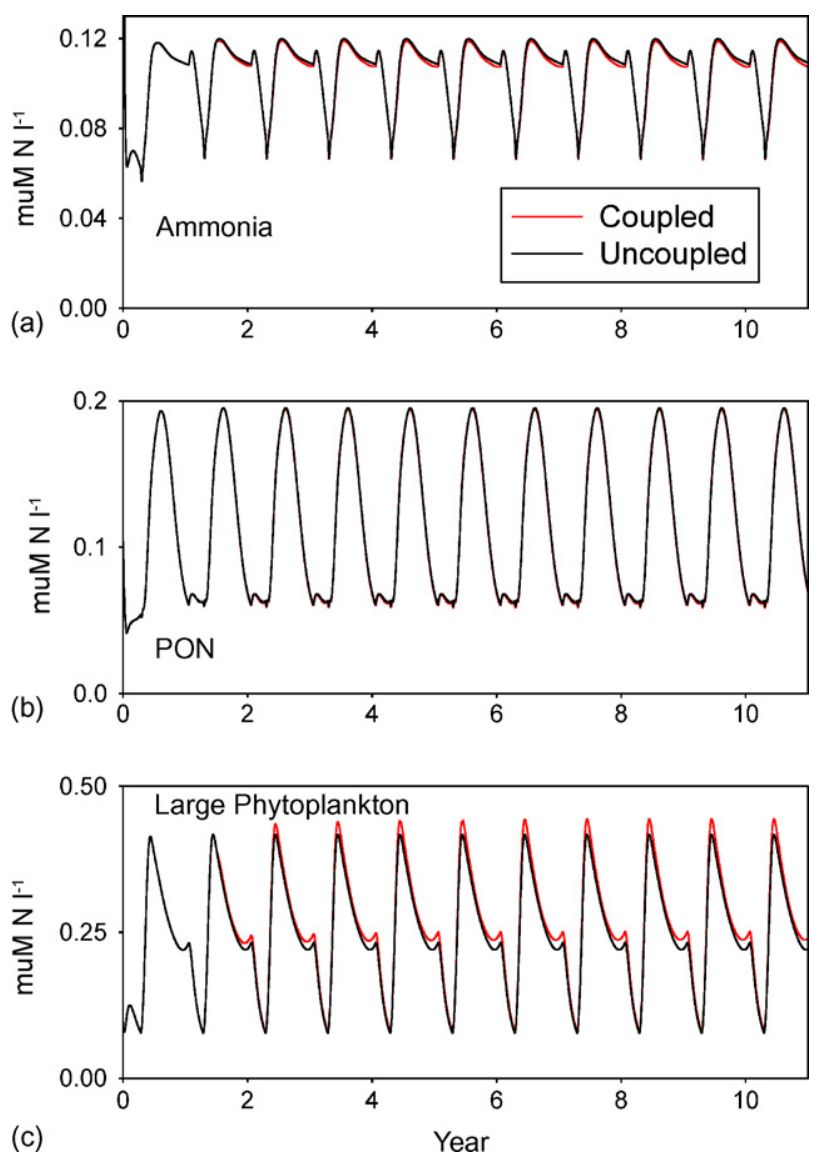

Fig. 9 - Predicted lower trophic level response of ammonia (a), PON (b), and large phytoplankton (c) from uncoupled and coupled simulations of the NEMURO.FISH model (from Rose et al., 2004, Fig. 4.5).

FISH), weight-at-age 5 and total biomass were most sensitive to the parameters associated with the allometric weight effect on consumption (kcmaxa and kcmacb; corresponding to $a_{C}$ and $b_{C}$ in Eq. (2.2.3.1)) and the allometric weight effect on respiration (krespa3 and krespb3; corresponding to $a_{R}$ and $b_{\mathrm{R}}$ in Eq. (2.2.5.1)). Also the parameter associated with the activity aspect of respiration (krespd3; $d_{R}$ of Eq. (2.2.5.4)) was important. These results were consistent for both the low herring biomass-high prey biomass year and the high herring biomass-low prey biomass year. Total biomass was more sensitive to kcmaxa than weight-at-age 5 , and weight-at-age 5 was more sensitive to krespb3 when herring biomass was high and prey biomass was low.

When the fish parameters were held constant and the NEMURO parameters were varied (middle row of Fig. 10, labeled LTL), total biomass and weight-at-age 5 were sensitive to the growth efficiency of their most important prey ZL (BetaZL), the temperature-dependent mortality of ZL (KMorZL), and the maximum photosynthetic rate of PL (VmaxL). When herring biomass was low and prey biomass high (middle row, left panel), optimum light intensity for PL (IoptL) was the next most important parameter, but when herring biomass was high and prey biomass low (middle row, right panel), mortality of ZL (MorZLO) became more impor- 

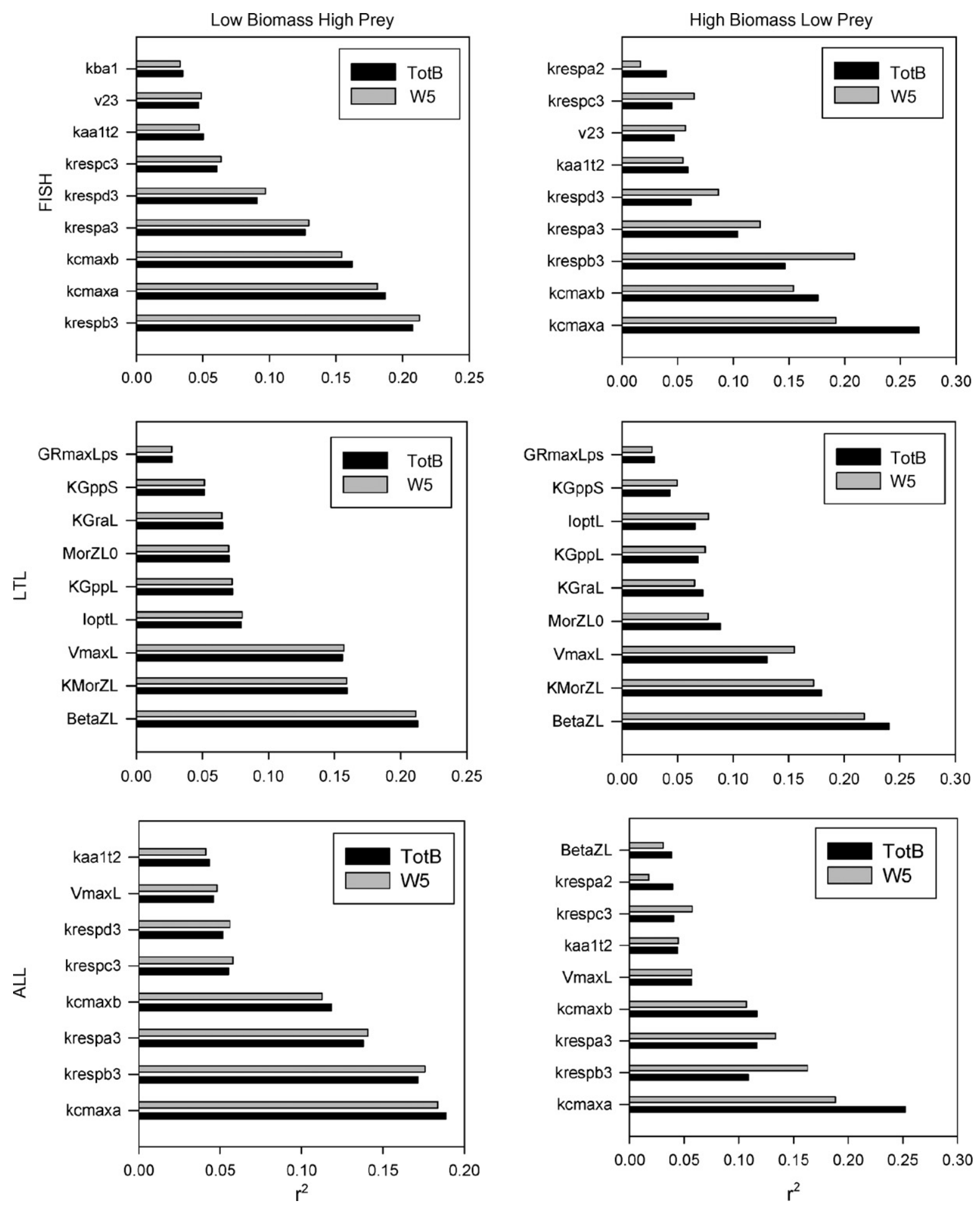

Fig. 10 - Results of the Monte Carlo uncertainty analysis showing correlations between parameter values and age-5 weight and total biomass for a year of low herring biomass and high prey biomass (left panels) and a year of high herring biomass and low prey biomass (right panels). NEMURO.FISH was run with all NEMURO parameters constant and only fish parameters allowed to vary (top row, labeled FISH), all fish parameters held constant and only NEMURO parameters were allowed to vary (middle row, labeled LTL), and for both NEMURO and fish parameters allowed to vary (bottom row, labeled ALL). Bars indicate the squared correlation coefficient between total biomass (black bars) and weight-at-age 5 (grey bars) with model parameters. Fish bioenergetics model parameter names (Table 1) can be matched to their uncertainty analysis variable names with the following key: kba1 = $b_{\mathrm{A}}$ for age group 0; kaa1t2 = $a_{\mathrm{A}}$ (for temp $\geq k \mathrm{ktu}$ ), age group 1; kcmaxa = $a_{\mathrm{C}} ; \mathrm{kcmaxb}=b_{\mathrm{C}}$; krespa2 $=a_{R}$ for age group 1; krespa3 $=a_{R}$ for age group 2 and older; krespb3 $=b_{R}$ for age group 2 and older; krespc3 $=c_{R}$ for age group 2 and older; krespd $3=d_{R}$ for age group 2 and older. All other variable names can be located in Tables 1 and 3 . 
tant. When herring biomass was high and prey biomass low (middle row, right panel), total biomass was sensitive to $\mathrm{ZL}$ growth efficiency (BetaZL) and weight-at-age 5 was sensitive to PL maximum photosynthetic rate (VmaxL).

When all parameters were varied (bottom row of Fig. 10, labeled ALL), total biomass and weight-at-age 5 were still very sensitive to the allometric weight effect on consumption and respiration, similar to when fish only parameters were varied (top row). Of interest was the fact that total biomass and weight-at-age 5 were sensitive to the maximum photosynthesis rate of PL (VmaxL) when herring biomass was high and prey biomass was low (bottom row, right panel). This implies a bottom-up control of herring growth when prey biomass was low.

Sensitive parameters reported here differ from those reported by Yoshie et al. (2007) for the NEMURO model. However, NEMURO used here was calibrated to the West Coast of Vancouver Island, whereas Yoshie et al. (2007) analyzed the NEMURO model calibrated to station A7 and ocean station $\mathrm{P}$ and they found differences in sensitivities between their two calibrated sets of parameter values.

\section{Discussion and conclusions}

There has been an increasing appreciation of climate effects on fish growth, recruitment, and population dynamics and recognition that effective resource management requires understanding and quantitative tools, including models, for predicting climate effects on fish populations. Bioenergetics modeling offers a sound approach for simulating the growth of fish in response to changing environmental conditions. The model described here provides a useful tool to examine the impact of climate change on the upper trophic levels of the marine ecosystem and to explore causes of observed "regimes" of varying productivity in exploited fish stocks.

We used the WCVI herring as a template for configuring NEMURO.FISH because the WCVI ecosystem and herring are well-studied and herring are an important link between the LTLs and top predators. Realistic herring weight-at-age and biomass were generated in 30-year simulations. Herring population dynamics were affected by herring growth rates, which affected spawning biomass that, with environmental forcing, affected subsequent young-of-the-year recruitment. Simulations under constant recruitment using coupled and uncoupled versions of NEMURO.FISH showed that herring have small to moderate effects on their zooplankton prey, which can then potentially affect nutrient dynamics. Monte Carlo uncertainty analysis showed that predicted weight-atage and population biomass were most sensitive to allometric parameters of maximum consumption and respiration, that other important parameters sometimes differed between the two output variables, and that LTL parameters can, at times, be important to fish dynamics.

We recognize that in a perfect world we should have simultaneously calibrated the coupled models. In some situations the grazing effect of herring could be important, but preliminary runs indicated that the impact of herring grazing on zooplankton were generally small and we knew that the LTL calibration data were poor temporally and by trophic level. Therefore we had to average over several data sources (Rose et al., 2007a). With this knowledge, and aiming towards simplified calibration, we separated the calibration into two steps. First we calibrated the NEMURO LTL to the observed available LTL data and then we calibrated the herring bioenergetics model to observed herring size-at-age data given the calibrated LTL. If we were able to go back and readjust the zooplankton mortality in NEMURO in a simultaneous calibration, the adjustment would be small because the effect of herring grazing on zooplankton in the coupled model would be small. Despite issues concerning calibration sequence, it still remains that this model is one of the few to dynamically link the HTL and LTL in a density-dependent manner. This perspective affords a small glimpse into how marine ecosystems may respond to climate change.

NEMURO.FISH has finite behaviors which may limit its ability to mimic many systems. But the benefit is that NEMURO.FISH is simple, general, and relies on information available for many fish species. NEMURO.FISH provides a useful tool to better understand intra- and inter-population variation in fish growth and survival, and to relate results to climate change and ecosystem carrying capacity. NEMURO.FISH can also be used to test the hypothesis that physical forcing factors regulate primary production and that the effect is apparent in zooplankton standing stock, through which it is transferred to variation in HTLs.

Ultimately we hope one day to forecast the consequences of climate variability on the ecosystems of the subarctic North Pacific. We believe coupled LTL and bioenergetics-based fish models will enhance our understanding of how climate conditions under different regimes can influence fish population dynamics and productivity.

\section{Acknowledgements}

We would like to thank the APN (Asia Pacific Network), North Pacific Marine Science Organization (PICES), the Global Ocean Ecosystem Dynamics Program (GLOBEC), the Heiwa-Nakajima Foundation of Japan, the Japan International Science and Technology Exchange Center, the City of Nemuro (Japan), and the Fisheries Research Agency (FRA) of Japan for sponsoring a series of workshops that resulted in the development of the NEMURO model and its coupling to fish growth dynamics. The authors are grateful to Dr. Yunne Shin and one anonymous reviewer for their very careful and thorough reading of our paper. Their many helpful suggestions and comments greatly improved the paper. This research is contribution FOCI-0517 to NOAA's Fisheries Oceanography Coordinated Investigations.

\section{REFERENCES}

Aneer, G., 1980. Estimates of feeding pressure on pelagic and benthic organisms by Baltic herring (Clupea harengus v. membras L.). Ophelia 1 (Suppl.), 265-275.

Apel, J.R., 1987. Principles of Ocean Physics. Academic Press, London, $634 \mathrm{pp}$.

Arrhenius, F., 1998a. Variable length of daily feeding period in bioenergetics modelling: a test with 0-group Baltic herring. J. Fish Biol. 52, 855-860. 
Arrhenius, F., 1998b. Food intake and seasonal changes in energy content of young Baltic Sea sprat (Sprattus sprattus L.). ICES J. Mar. Sci. 55, 319-324.

Arrhenius, F., Hansson, S., 1996. Growth and seasonal changes in energy content of young Baltic Sea herring (Clupea harengus L.). ICES J. Mar. Sci. 53, 792-801.

Beamish, F.W.H., 1974. Apparent specific dynamic action of largemouth bass, Micropterus salmoides. J. Fish. Res. Bd. Can. 31, 1763-1769.

Beamish, F.W.H., Trippel, E.A., 1990. Heat increment: a static or dynamic dimension in bioenergetic models? Trans. Am. Fish. Soc. $119,649-661$.

Beyer, J.E., Laurence, G.C., 1980. A stochastic model of larval fish growth. Ecol. Modell. 8, 109-132.

Brown, J.H., Gillooly, J.F., Allen, A.P., Savage, V.M., West, G.B., 2004. Toward a metabolic theory of ecology. Ecology 85, 1771-1789.

Carlotti, F., Giske, J., Werner, F.E., 2000. Modeling zooplankton dynamics. In: Harris, R.P., Wiebe, P.H., Lenz, J., Skjoldal, H.R., Huntley, M. (Eds.), ICES Zooplankton Methodology Manual. Academic Press, pp. 571-667.

Cury, P., Bakun, A., Crawford, R.J., Jarre, A., Quinones, R.A., Shannon, L.J., Verheye, H.M., 2000. Small pelagics in upwelling systems: patterns of interaction and structural changes in "wasp-waist" ecosystems. ICES J. Mar. Sci. 57 (3), 603-618.

De Silva, S.S., Balbontin, F., 1974. Laboratory studies on food intake, growth and food conversion of young herring, Clupea harengus (L.). J. Fish Biol. 6, 645-658.

Elliott, J.M., 1976. The energetics of feeding, metabolism, and growth of brown trout (Salmo trutta L.) in relation to body weight, water temperature, and ration size. J. Anim. Ecol. 45, 923-948.

Essington, T.E., 2003. Development and sensitivity analysis of bioenergetics models for skipjack tuna and albacore: a comparison of alternative life histories. Trans. Am. Fish. Soc. 132 (4), 759-770.

Fennel, W., Neumann, T., 2004. Introduction to the modelling of marine ecosystems, Elsevier Oceanographic Series 72, Amsterdam, $297 \mathrm{pp}$

Flath, L.E., Diana, J.S., 1985. Seasonal energy dynamics of the alewife in southeastern Lake Michigan. Trans. Am. Fish. Soc. 114, 328-337.

Foy, R.J., Paul, A.J., 1999. Winter feeding and changes in somatic energy content of age-0 Pacific herring in Prince William Sound, Alaska. Trans. Am. Fish. Soc. 128, 1193-1200.

Haegele, C.W., 1997. The occurrence, abundance and food of juvenile herring and salmon in the Strait of Georgia, British Columbia in 1990 to 1994. Can. Man. Rep. Fish. Aquat. Sci. 2390, 124

Hansen, M.J., Boisclair, D., Brandt, S.B., Hewett, S.W., Kitchell, J.F., Lucas, M.C., Ney, J.J., 1993. Applications of bioenergetics models to fish ecology and management: where do we go from here? Trans. Am. Fish. Soc. 122, 1019-1030.

Hanson, P.C., Johnson, T.B., Schindler, D.E., Kitchell, J.F., 1997. Fish bioenergetics 3.0 for Windows. Technical Report WISCU-T-97-001. University of Wisconsin Sea Grant Institute, Madison, WI, USA.

Hartman, K.J., Brandt, S.B., 1995. Comparative energetics and the development of bioenergetics models for sympatric estuarine piscivores. Can. J. Fish. Aquat. Sci. 52 (8), 1647-1666.

Hay, D.E., McCarter, P.B., 1997. Continental shelf area, distribution, abundance and habitat of herring in the North Pacific. In: Proceedings of the Wakefield Fisheries Symposium. Alaska Sea Grant College Program 97-01, pp. 559-572.

Hay, D.E., Brett, J.R., Bilinski, E., Smith, D.T., Donaldson, E.M., Hunter, G.A., Solmie, A.V., 1988. Experimental impoundments of prespawning Pacific herring (Clupea harengus pallasi): effects of feeding and density on maturation, growth, and proximate analysis. Can. J. Fish. Aquat. Sci. 45, 388-398.
Hay, D.E., Outram, D.N., McKeown, B.A., Hurlburt, M., 1987. Ovarian development and oocyte diameter as maturation criteria in Pacific herring (Clupea harengus pallasi). Can. J. Fish. Aquat. Sci. 44, 1496-1502.

Hay, D.E., Toresen, R., Stephenson, R., Thompson, M., Claytor, R., Funk, F., Ivshina, E., Jakobsson, J., Kobayashi, T., McQuinn, I., Melvin, G., Molloy, J., Naumenko, N., Oda, K.T., Parmanne, R., Power, M., Radchenko, V., Schweigert, J., Simmonds, J., Sjöstrand, B., Stevenson, D.K., Tanasichuk, R., Tang, Q., Watters, D.L., Wheeler, J., 2001. Taking stock: an inventory and review of world herring stocks in 2000. In: Funk, F., Blackburn, J., Hay, D., Paul, A.J., Stepenson, R., Toresen, R., Witherell, D. (Eds.), Herring: Expectations for a New Millennium, AK-SG-01-04. University of Alaska Sea Grant, Fairbanks, pp. 381-454

Hettler, W.F., 1976. Influence of temperature and salinity on routine metabolic rate and growth of young Atlantic menhaden. J. Fish Biol. 8, 55-65.

Hermann, A.J., Hinckley, S., Megrey, B.A., Napp, J.M., 2001. Applied and theoretical considerations for constructing spatially explicit individual-based models of marine larval fish that include multiple trophic levels. ICES J. Mar. Sci. 58 (5), 1030-1041.

Hinckley, S., Hermann, A.J., Megrey, B.A., 1996. Development of a spatially explicit, individual-based model of marine fish early life history. Mar. Ecol. Prog. Ser. 139, 47-68.

Ito, S., Megrey, B.A., Kishi, M.J., Mukai, D., Kurita, Y., Ueno, Y., Yamanaka, Y., 2007. On the interanual variability of the growth of Pacific saury (Cololabis saira): a simple 3-box model using NEMURO.FISH. Ecol. Modell. 202, 174-183.

Ito, S., Kishi, M.J., Kurita, Y., Oozeki, Y., Yamanaka, Y., Megrey, B.A., Werner, F.E., 2004. Initial design for a fish bioenergetics model of Pacific saury coupled to a lower trophic ecosystem model. Fish. Oceanogr. 13 (Suppl. 1), 111-124.

Kerr, S.R., Dickie, L.M., 1985. Bioenergetics of 0+ Atlantic herring (Clupea harengus harengus). Can. J. Fish. Aquat. Sci. 42 (Suppl. 1), 105-110.

Kiørboe, T., Munk, P., Richardson, K., 1987. Respiration and growth of larval herring Clupea harengus: relation between specific dynamic action and growth efficiency. Mar. Ecol. Prog. Ser. 40, 1-10.

Kishi, M.J., Kashiwai, M., Ware, D.M., Megrey, B.A., Eslinger, D.L., Werner, F.E., Aita, M.N., Azumaya, T., Fujii, M., Hashimoto, S., Huang, D., Iizumi, H., Ishida, Y., Kang, S., Kantakov, G.A., Kim, H.-C., Komatsu, K., Navrotsky, V.V., Smith, S.L., Tadokoro, K., Tsuda, A., Yamamura, O., Yamanaka, Y., Yokouchi, K., Yoshie, N., Zhang, J., Zuenko, Y.I., Zvalinsky, V.I., 2007. NEMURO-A lower trophic level model for the North Pacific marine ecosystem. Ecol. Modell. 202, 12-25.

Kishi, M.J., Okunishi, T., Yamanaka, Y., 2004. A comparison of simulated particle fluxes using NEMURO and other ecosystem models in the western North Pacific. J. Oceanogr. 60, 63-73.

Kitchell, J.F., Stewart, D.J., Weininger, D., 1977. Applications of a bioenergetics model to yellow perch (Perca flavescens) and walleye (Stizostedion vitreum vitreum). J. Fish. Res. Bd. Can. 34, 1922-1935.

Klumb, R.A., 2003. The role of embayments and nearshore habitats of Lake Ontario as nursery grounds for young-of-the-year alewives Alosa pseudoharengus and other species. PhD Dissertation. Cornell University, Ithaca, NY, 241 pp.

Klumb, R.A., Rudstam, L.G., Mills, E.L., 2003. Comparison of alewife young-of-the-year and adult respiration and swimming speed bioenergetic model parameters: implications of extrapolation. Trans. Am. Fish. Soc. 132, 1089-1103.

Klumpp, D.W., von Westernhagen, H., 1986. Nitrogen balance in marine fish larvae: influence of developmental stage and prey 
density. Mar. Biol. 93, 189-199.

Kooijman, S.A.L.M., 1993. Dynamic Energy Budgets for Biological Systems. Cambridge University Press, New York.

Lassuy, D.R., 1989. Species profiles: life histories and environmental requirements of coastal fishes and invertebrates (Pacific Northwest)-Pacific herring. US Fish and Wildlife Service Biological Report 82(11.126). US Army Corps of Engineers, TR-EL-82-4.

Laurence, G.C., 1976. Caloric content of some North Atlantic calanoid copepods. Fish. Bull. U.S. 78, 218-220.

Le Quéré, C., Harrison, S.P., Prentice, I.C., Buitenhuis, E.T., Aumont, O., Bopp, L., Claustre, H., Cotrim da Cunha, L., Geider, R., Giraud, X., Klaas, C., Kohfeld, K., Legendre, L., Manizza, L., Platt, T., Rivkin, R.B., Sathyendranath, S., Uitz, J., Watson, A.J., Wolf-Gladrow, D., 2005. Ecosystem dynamics based on plankton functional types for global ocean biogeochemistry models. Global Change Biol. 11 (11), 1040-2060, doi:10.1111/j.1365-2486.2005.001004.x.

Letcher, B.H., Rice, J.A., Crowder, L.B., Rose, K.A., 1996. Variability in survival of larval fish: disentangling components with a generalized individual-based model. Can. J. Fish. Aquat. Sci. $53,787-801$.

Limburg, K.E., 1994. Ecological constraints on growth and migration of juvenile American shad (Alosa sapidissima Wilson) in the Hudson River Estuary, New York. Doctoral Dissertation. Cornell University, Ithaca, NY.

Mackas, D.L., Peterson, W.T., Zamon, J.E., 2004. Comparisons of interannual biomass anomalies of zooplankton communities along the continental margins of British Columbia and Oregon. Deep Sea Res. II 51, 875-896.

Maes, J., Limburg, K.E., Van de Putte, A., Ollevier, F., 2005. A spatially explicit, individual-based model to assess the role of estuarine nurseries in the early life history of North Sea herring, Clupea harengus. Fish. Oceanogr. 1491, 17-31.

McKay, M.D., Beckman, R.D., Conover, W.J., 1979. A comparison of three methods for selecting values of input variables in the analysis of output from computer code. Technometrics 21, 239-245.

Muir, B.S., Niimi, A.J., 1972. Oxygen consumption of the euryhaline fish aholehole (Kuhlia sandvicensis) with reference to salinity, swimming, and food consumption. J. Fish. Res. Bd. Can. 29, 67-77.

Ney, J.J., 1990. Trophic economics in fisheries-assessment of demand-supply relationships between predators and prey. Rev. Aquat. Sci. 2, 55-81.

Ney, J.J., 1993. Bioenergetics modeling today: growing pains on the cutting edge. Trans. Am. Fish. Soc. 122, 736-748.

Paul, A.J., Paul, J.M., 1998. Spring and summer whole-body energy content of Alaskan juvenile Pacific herring. AK Fish. Res. Bull. 5, 131-136.

Paul, A.J., Paul, J.M., Brown, E.D., 1998. Fall and spring somatic energy content for Alaskan Pacific herring (Clupea pallasi Valenciennes 1847) relative to age, size and sex. J. Exp. Mar. Biol. Ecol. 223, 133-142.

Post, J.R., Lee, J.A., 1996. Metabolic ontogeny of teleost fishes. Can. J. Fish. Aquat. Sci. 53, 910-923.

Rejas, D., Declerck, S., Auwerkerken, J., Tak, P., De Meester, L., 2005. Plankton dynamics in a tropical floodplain lake: fish, nutrients, and the relative importance of bottom-up and top-down control. Fresh Biol. 50 (1), 52-69.

Robinson, C.L.K., Ware, D.M., 1999. Simulated and observed response of the southwest Vancouver Island pelagic ecosystem to oceanic conditions in the 1990s. Can. J. Fish. Aquat. Sci. 56, 2433-2443.

Rose, K.A., Megrey, B.A., Werner, F.E., Ware, D.M., 2007 a. Calibration of the NEMURO nutrient-phytoplankton-zooplankton food web model to a coastal ecosystem: evaluation of an automated calibration approach. Ecol. Modell. 202, 38-51.

Rose, K.A., Werner, F.E., Megrey, B.A., Aita, M.N., Yamanaka, Y., Hay, D.E., 2007b. Simulated herring growth responses in the Northeastern Pacific to historic temperature and zooplankton conditions generated by the 3-dimensional NEMURO nutrient-phytoplankton-zooplankton model. Ecol. Modell. 202, 184-195.

Rose, K.A., Megrey, B.A., Hay, D.E., Werner F.E., 2004. Coupling NEMURO to herring bioenergetics. In: Kishi, M.J. (Ed.) Report of the MODEL Task Team Second Workshop to Develop a Marine Ecosystem Model of the North Pacific Ocean Including Pelagic Fishes. PICES Scientific Rep. No. 27, pp. 5-15.

Rose, K.A., Rutherford, E.S., McDermot, D.S., Forney, J.L., Miles, E.L., 1999. Individual-based model of yellow perch and walleye populations in Oneida Lake. Ecol. Monogr. 69 (2), 127-154.

Rose, K.A., Smith, E.P., Gardner, R.H., Brenkert, A.L., Bartell, S.M., 1991. Parameter sensitivities, Monte Carlo filtering, and model forecasting under uncertainty. J. Forecast. 10, 117-133.

Rudstam, L.G., 1988. Exploring the dynamics of herring consumption in the Baltic: applications of an energetic model of fish growth. Kieler Meeresforschung Sonderheft 6 , 312-322.

Runge, J.A., Franks, P.J.S., Gentleman, W.C., Megrey, B.A., Rose, K.A., Werner, F.E., Zakardjian, B., 2004. Diagnosis and prediction of variability in secondary production and fish recruitment processes: developments in physical-biological modelling. The Global Coastal Ocean: Multi-Scale Interdisciplianary Processes, The Sea, vol. 13, pp. 413-473 (Chapter 13).

Schweigert, J., 2004. Stock assessment for British Columbia herring in 2003 and forecasts of the potential catch in 2004. Canadian Science Advisory Secretariat Research Document 2004/005. Fisheries and Oceans Canada, Ottawa. Available: http://www.dfo-mpo.gc.ca/csas/ (June 2005).

Schweigert, J., Funk, F., Oda, K., Moore, T., 2002. Herring size-at-age variation in the North Pacific. In PICES-GLOBEC International Program on Climate Change and Carrying Capacity, Scientific Report No. 20, pp. 47-57.

Stewart, D.J., Binkowski, F.P., 1986. Dynamics of consumption and food conversion by Lake Michigan alewives: an energetics-modeling synthesis. Trans. Am. Fish. Soc. 115, 643-661.

Tanasichuk, R.W., 1997. Influence of biomass and ocean climate on the growth of Pacific herring (Clupea pallasi) from the southwest coast of Vancouver Island. Can. J. Fish. Aquat. Sci. 54, 2782-2788.

Tanasichuk, R.W., 2002. Implications of interannual variability in euphausiid population biology for fish production along the south-west coast of Vancouver Island: a synthesis. Fish. Oceanogr. 11, 18-30.

Tang, Q., Sun, Y., Zhang, B., 2003. Bioenergetics models for seven species of marine fish. J. Fish. China/Shuichan Xuebao 27 (5), 443-449.

Thornton, K.W., Lessem, A.S., 1978. A temperature algorithm for modifying biological rates. Trans. Am. Fish. Soc. 107, 284-287.

Vlymen, W.J., 1977. A mathematical model of the relationship between larval anchovy (Engraulis mordax) growth, prey microdistribution, and larval behavior. Environ. Biol. Fish. 2 (3), 211-233.

Ware, D.M., Thomson, A.S., 2005. Bottom-up ecosystem trophic dynamics determine fish production in the northeast Pacific. Science 308 (5726), 1280-1284.

Ware, D.M., 1975. Growth, metabolism, and optimal swimming speed of a pelagic fish. J. Fish. Res. Bd. Can. 32, 33-41.

Werner, F.E., Perry, R.I., Lough, R.G., Naimie, R.G., 1996. Trophodynamic and advective influences on Georges Bank larval cod and haddock. Deep Sea Res. II 43, 1793-1822. 
Williams, E.H., Quinn, T.J., 2000a. Pacific herring, Clupea pallasi, recruitment in the Bering Sea and north-east Pacific Ocean. I. Relationships among different populations. Fish. Oceanogr. 9, 285-299.

Williams, E.H., Quinn, T.J., 2000b. Pacific herring, Clupea pallasi, recruitment in the Bering Sea and north-east Pacific Ocean. II. Relationships to environmental variables and implications for forecasting. Fish. Oceanogr. 9, 300-315.

Winberg, G.G., 1956. Rate of metabolism and food requirements of fishes. Belorussian University, Minsk. Translated from
Russian: Fisheries Research Board of Canada Translation Service 194, 1960, Ottawa.

Yamanaka, Y., Yoshie, N., Fuijii, M., Aita, M.N., Kishi, M.J., 2004. An ecosystem model coupled with nitrogen-silicon-carbon cycles applied to station A7 in the northwest Pacific. J. Oceanogr. 60, 227-241.

Yoshie, N., Yamanaka, Y., Rose, K.A., Eslinger, D.L., Ware, D.M., Kishi, M.J., 2007. Parameter sensitivity study of a lower trophic level marine ecosystem model NEMURO. Ecol. Modell. 202, 26-37. 